LA WAE NCE LIWEAMCAE NATIONAL LABOAATORY

\title{
Validation of Reinforced Concrete Modeling Capabilities for Seismic Response
}

S.W. Alves, C.R. Noble

Structural and Applied Mechanics Group

September 2007
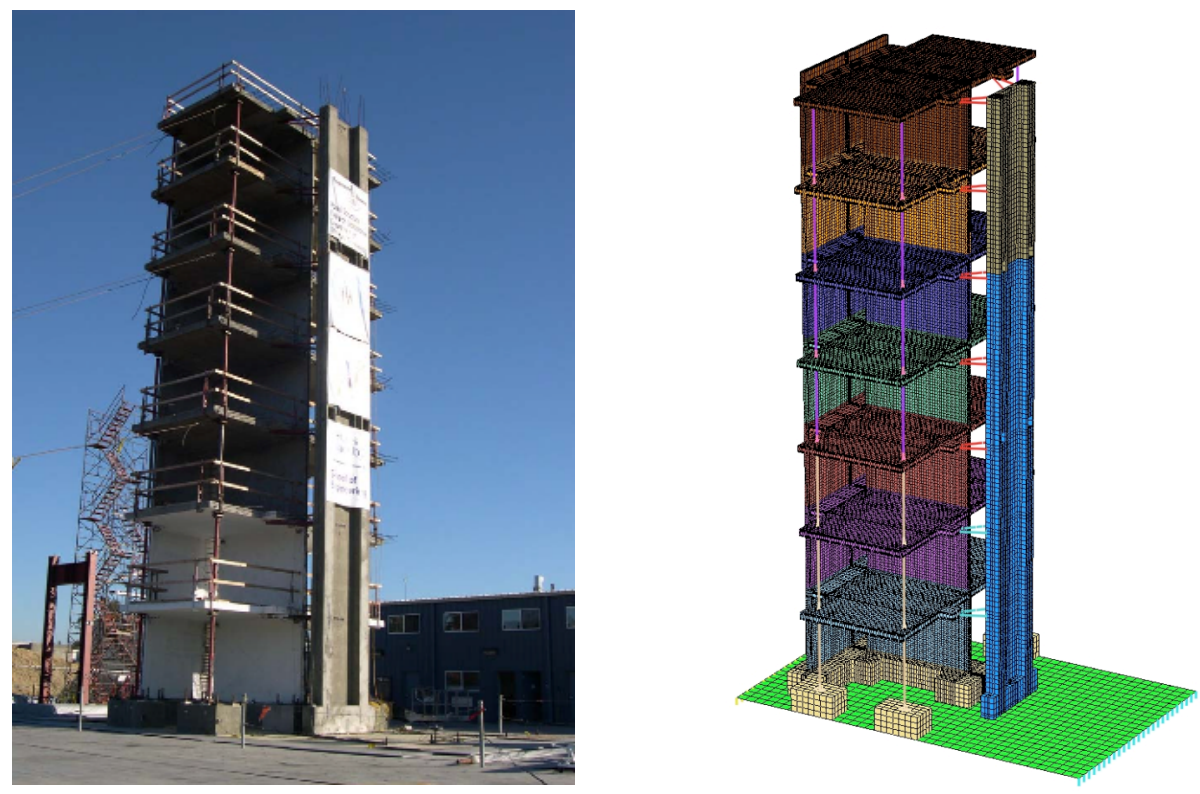
This document was prepared as an account of work sponsored by an agency of the United States Government. Neither the United States Government nor the University of California nor any of their employees, makes any warranty, express or implied, or assumes any legal liability or responsibility for the accuracy, completeness, or usefulness of any information, apparatus, product, or process disclosed, or represents that its use would not infringe privately owned rights. Reference herein to any specific commercial product, process, or service by trade name, trademark, manufacturer, or otherwise, does not necessarily constitute or imply its endorsement, recommendation, or favoring by the United States Government or the University of California. The views and opinions of authors expressed herein do not necessarily state or reflect those of the United States Government or the University of California, and shall not be used for advertising or product endorsement purposes.

This work was performed under the auspices of the U.S. Department of Energy by University of California, Lawrence Livermore National Laboratory under Contract W-7405-Eng-48. 


\section{Table of Contents}

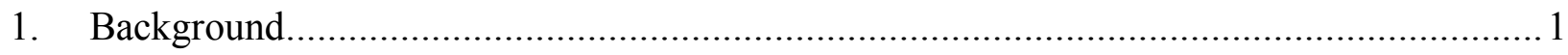

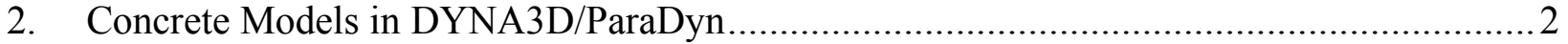

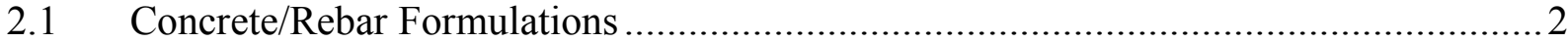

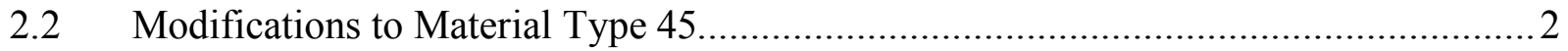

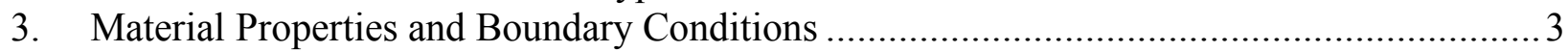

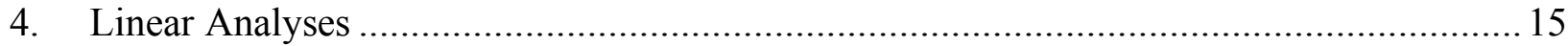

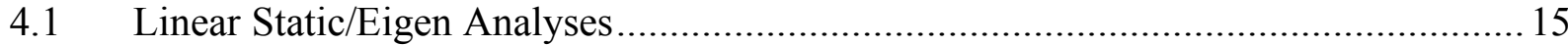

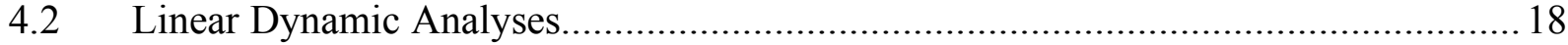

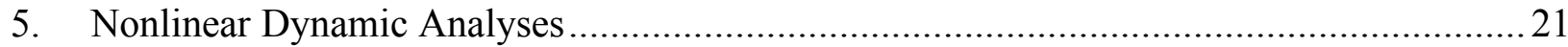

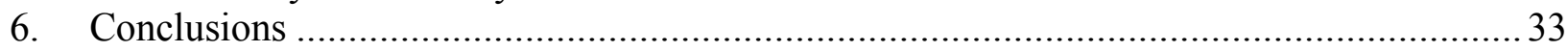

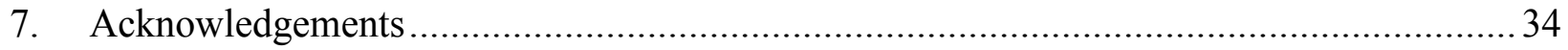

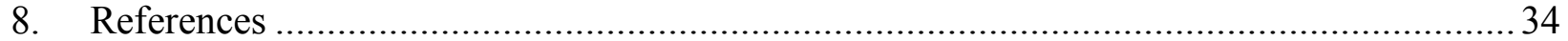




\section{List of Figures}

Figure 1. Test structure at UCSD ............................................................................... 1

Figure 2. Representative concrete stress-strain curve for properties supplied by UCSD (left), and schematic of concrete placement locations (right) ............................................................. 4

Figure 3. Finite element model of concrete cylinder for unconfined compression test ................. 5

Figure 4. Simulated stress-strain curves compared to experimentally measured curves of concrete

cylinder unconfined compression tests for $\mathrm{c} 2$ concrete placement...................................... 6

Figure 5. Simulated stress-strain curves compared to experimentally measured curves of concrete cylinder unconfined compression tests for $\mathrm{c} 3$ concrete placement......................................6 6

Figure 6. Simulated stress-strain curves compared to experimentally measured curves of concrete cylinder unconfined compression tests for $\mathrm{c} 5$ concrete placement..................................... 6

Figure 7. Simulated stress-strain curve compared to experimentally measured curves of concrete cylinder unconfined compression tests for $\mathrm{c} 7$ concrete placement...................................... 7

Figure 8. Simulated stress-strain curve compared to experimentally measured curves of concrete cylinder unconfined compression tests for $\mathrm{c} 9$ concrete placement.

Figure 9. Simulated stress-strain curve compared to experimentally measured curves of concrete cylinder unconfined compression tests for $\mathrm{c} 11$ concrete placement.................................... 7

Figure 10. Simulated stress-strain curve compared to experimentally measured curves of concrete cylinder unconfined compression tests for $\mathrm{c} 13$ concrete placement........................ 8

Figure 11. Simulated stress-strain curve compared to experimentally measured curves of concrete cylinder unconfined compression tests for $\mathrm{c} 15$ concrete placement........................8

Figure 12. Simulated stress-strain curve compared to experimentally measured curves of concrete cylinder unconfined compression tests for $\mathrm{c} 17$ concrete placement........................ 8

Figure 13. Simulated stress-strain curve compared to experimentally measured curves of concrete cylinder unconfined compression tests for $\mathrm{c} 18$ concrete placement....................... 9

Figure 14. Representative steel stress-strain curve for properties supplied by UCSD .................. 11

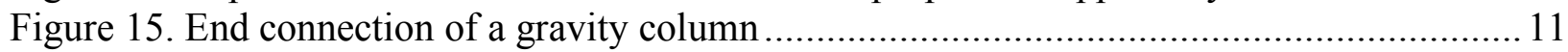

Figure 16. Braces connecting the post-tensioned column to a floor slab .................................. 12

Figure 17. Finite element model of the 7-story structure situated on the shake table platen modeled as a rigid shell with springs at both ends of the platen ...................................... 13

Figure 18. Acceleration time histories for the four earthquakes .............................................. 14

Figure 19. Linear finite element models for NIKE3D analyses with shake table platen (left) and

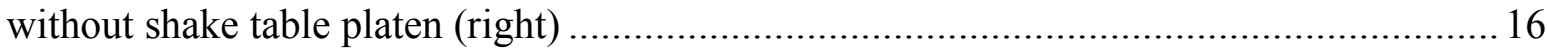

Figure 20. First torsional mode (left), first longitudinal mode (middle), and second longitudinal mode (right) for the model with a table platen rotational stiffness of $0.5 \times 10^{7} \mathrm{kip}-\mathrm{ft} / \mathrm{rad} . \ldots . .17$

Figure 21. First torsional mode (left), first longitudinal mode (middle), and second longitudinal mode (right) for the model with no table platen ............................................................ 17

Figure 22. Finite element model of the structure with the shake table platen for linear dynamic simulations in ParaDyn

Figure 23. Frequency response of the simulated (linear model) roof displacements for the first earthquake compared to the frequency response of the measured roof displacement..........20

Figure 24. Frequency response of the simulated (linear model) roof displacements for the fourth earthquake compared to the frequency response of the measured roof displacement ..........21

Figure 25. Finite element model of the structure with the shake table platen for nonlinear simulations in ParaDyn 
Figure 26. Time history (left) and frequency response (right) of the computed roof displacement for the model with a table platen rotational stiffness of $0.5 \times 10^{7} \mathrm{kip}-\mathrm{ft} / \mathrm{rad}$ compared to the measured roof displacement for the first earthquake

Figure 27. Time history (left) and frequency response (right) of the computed roof displacement for the model with a table platen rotational stiffness of $1.0 \times 10^{7} \mathrm{kip}-\mathrm{ft} / \mathrm{rad}$ compared to the measured roof displacement for the first earthquake ................................................ 23

Figure 28. Time history (left) and frequency response (right) of the computed roof displacement for the model with a table platen rotational stiffness of $2.0 \times 10^{7} \mathrm{kip}-\mathrm{ft} / \mathrm{rad}$ compared to the measured roof displacement for the first earthquake

Figure 29. Time history (left) and frequency response (right) of the computed roof displacement for the model with a table platen rotational stiffness of $3.5 \times 10^{7} \mathrm{kip}-\mathrm{ft} / \mathrm{rad}$ compared to the measured roof displacement for the first earthquake.

Figure 30. Time history (left) and frequency response (right) of the computed roof displacement for the model with no table platen compared to the measured roof displacement for the first earthquake.

Figure 31. Concrete damage measure at the end of the first earthquake outside of the web wall (left) and in the middle of the web wall at the symmetry plane (right) 26

Figure 32. Time history (left) and frequency response (right) of the computed roof displacement for the model with a table platen rotational stiffness of $0.5 \times 10^{7} \mathrm{kip}-\mathrm{ft} / \mathrm{rad}$ compared to the measured roof displacement for the second earthquake

Figure 33. Time history (left) and frequency response (right) of the computed roof displacement for the model with no table platen compared to the measured roof displacement for the second earthquake

Figure 34. Time history (left) and frequency response (right) of the computed roof displacement for the model with a table platen rotational stiffness of $0.5 \times 10^{7} \mathrm{kip}-\mathrm{ft} / \mathrm{rad}$ compared to the measured roof displacement for the third earthquake.

Figure 35. Time history (left) and frequency response (right) of the computed roof displacement for the model with no table platen compared to the measured roof displacement for the third earthquake. .28

Figure 36. Time history (left) and frequency response (right) of the computed roof displacement for two levels of damping in the model with a table platen rotational stiffness of $0.5 \times 10^{7}$ kip-ft/rad compared to the measured roof displacement for the second earthquake 29

Figure 37. Time history (left) and frequency response (right) of the computed roof displacement for two levels of damping in the model with a table platen rotational stiffness of $0.5 \times 10^{7}$ kip- $\mathrm{ft} / \mathrm{rad}$ compared to the measured roof displacement for the third earthquake...... 29

Figure 38. Time history (left) and frequency response (right) of the computed roof displacement for two "lambda stretch" factors in the model with a table platen rotational stiffness of $0.5 \times 10^{7} \mathrm{kip}-\mathrm{ft} / \mathrm{rad}$ compared to the measured roof displacement for the first earthquake.... 30

Figure 39. Time history (left) and frequency response (right) of the computed roof displacement for two "lambda stretch" factors in the model with a table platen rotational stiffness of $0.5 \times 10^{7} \mathrm{kip}-\mathrm{ft} / \mathrm{rad}$ compared to the measured roof displacement for the second earthquake 30

Figure 40. Time history (left) and frequency response (right) of the computed roof displacement for the model with a table platen rotational stiffness of $0.5 \times 10^{7} \mathrm{kip}-\mathrm{ft} / \mathrm{rad}$ compared to the measured roof displacement for the fourth earthquake. 
Figure 41. Time history (left) and frequency response (right) of the computed roof displacement for the model with no table platen compared to the measured roof displacement for the

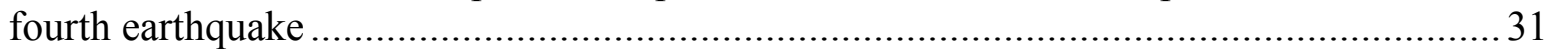

Figure 42. Concrete damage measure at the start of the fourth earthquake outside of the web wall

(left) and in the middle of the web wall at the symmetry plane (right) .32

Figure 43. Concrete damage measure at the end of the fourth earthquake outside of the web wall (left) and in the middle of the web wall at the symmetry plane (right) 32 


\section{List of Tables}

Table 1. Concrete properties supplied by UCSD .................................................... 4

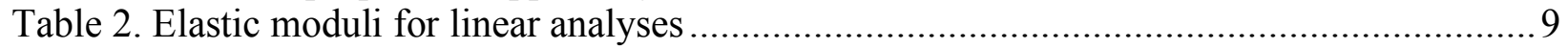

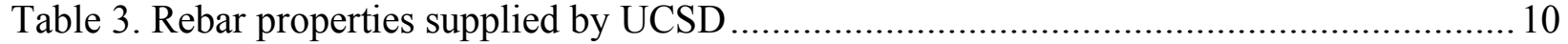

Table 4. Estimates of rotational flexibility for the shake table and the foundation/shake table provided by UCSD........................................................................................ 13

Table 5. Natural frequencies of the first torsional, first longitudinal and second longitudinal

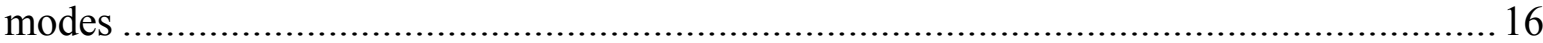

Table 6. Peak values of the simulated (linear model) and measured roof displacements for four earthquake ground motions .............................................................................. 20

Table 7. Peak values of the simulated (nonlinear model) and measured roof displacement for the

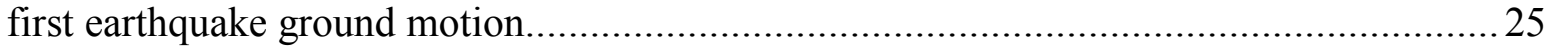




\section{Background}

Shake table tests were performed on a full-scale 7-story slice of a reinforced concrete building at UC San Diego between October 2005 and January 2006. The tests were performed on the NEES Large High-Performance Outdoor Shake Table (LHPOST) at the Engelkirk Structural Engineering Center of UCSD. The structure was subjected to four uniaxial earthquake ground motions of increasing amplitude. Details of the building construction were provided by UCSD. The structure is shown in Figure 1. Accelerometers and strain gauges were placed throughout the structure during the experiment, and the data have been provided by NEES/UCSD [1].

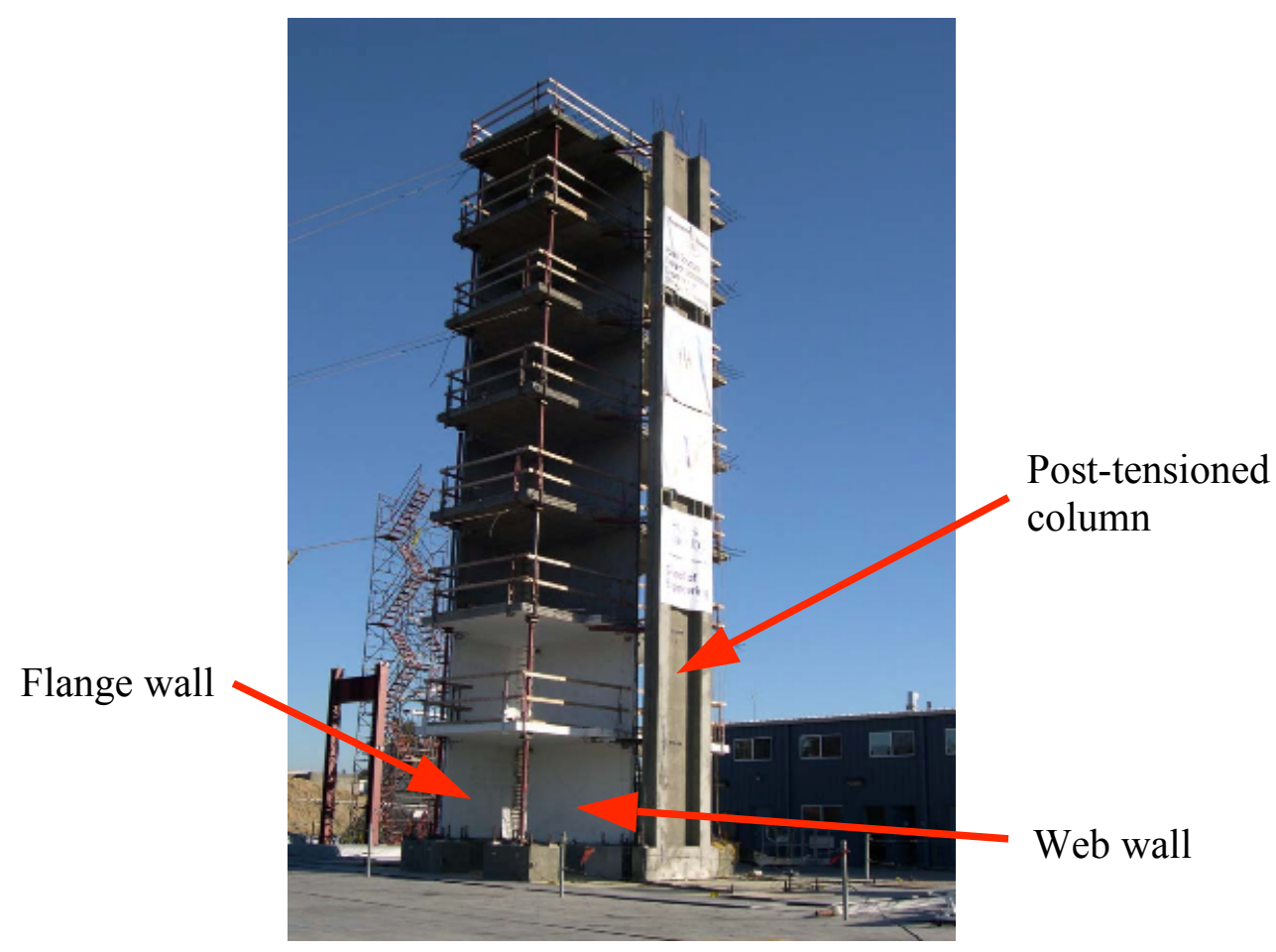

Figure 1. Test structure at UCSD

The experiment provides full-scale results for use in assessing the capability of the homogenized rebar model in DYNA3D/Paradyn [2,3] to model reinforced concrete structures subjected to seismic events. The homogenized rebar model is a composite model based on the DTRA concrete model developed by Karagozian \& Case $[4,5,6]$. Work has been done to validate this material model for use in blast simulations, but seismic simulations require longer durations. Previous work [7] demonstrated that a numerical instability existed in the concrete material model that could arise during long duration simulations. Also, difficulties persisted in modeling the response of the structure accurately up to the point in the simulation at which the numerical instability caused the code to terminate. The work presented in this report describes efforts to correct the material model to prevent the numerical instability, and to refine the modeling approach to improve correlation with the experimental response. 


\section{Concrete Models in DYNA3D/ParaDyn}

\subsection{Concrete/Rebar Formulations}

The DTRA concrete model $[4,5,6]$ (material type 45 in DYNA3D [2]) decouples the volumetric and deviatoric responses, and it uses an equation of state to define pressures and unloading bulk moduli as functions of volumetric strain. There are three independent failure surfaces that define the plastic behavior of the concrete. The failure surfaces are based on the second invariant of the deviatoric stress tensor. The material is linear up to the yield failure surface. Then the material transitions to the maximum failure surface, and after reaching the maximum strength the material softens until reaching the residual failure surface. There is a damage measure associated with these failure surfaces. Until yield is reached, the damage measure is 0 . The value is 1 at the maximum surface and 2 when the residual surface is reached. Material type 65 in DYNA3D is an update of material type 45 that generates all of the parameters for material type 45 using only the unconfined compressive strength of the concrete $[2,8]$.

The homogenized rebar model used in the simulations is material type 66 in DYNA3D [2,4]. The DTRA concrete model (material type 45) is used to model the concrete, and it is augmented with a rebar model that can have rebar in up to three arbitrary directions with differing properties. Strain-rate dependence, work hardening and tensile failure are included in the rebar model. Only axial response is considered in the rebar. The homogenized rebar model is attractive to use because of its relative efficiency in computation and mesh generation compared to explicitly modeling the rebar with brick or beam elements.

\subsection{Modifications to Material Type 45}

In previous versions of DYNA3D/ParaDyn, the DTRA Concrete model (material type 45) could become unstable. It was a rare occurrence that appears to be related to long simulation duration, which provides opportunity for the conditions for the instability to develop. It is also possible that the occurrence of the instability is related to the use of material type 45 and material type 66 (the homogenized rebar model) in conjunction with each other, but this cannot be verified.

The cause of the instability was determined to be the calculation of a quantity related to the effective plastic strain and damage parameter increments. In certain situations the denominator of this term can become very small or negative and this leads to the calculation of a very large value, which then leads to the calculation of a very large pressure for the element. This nonphysical behavior causes elements to invert and forces the simulation to terminate. Once the cause of the instability was determined, it was discovered that newer versions of the Karagozian $\&$ Case model already had a modification to prevent this numerical anomaly. The modification involves scaling the stress in an element to zero if the denominator of the effective plastic strain increment quantity is very small or negative. This modification was implemented in material type 45 , and it successfully prevents DYNA3D/ParaDyn from terminating due to inverted elements caused by the numerical anomaly. However, as will be discussed in more detail in Section 5, it is believed that large effective plastic strain increments and pressure increments can still be calculated for an element. The stress is scaled to zero before an element is forced to invert, but large deformation is computed before this mechanism is triggered. While this does 
not prevent simulations from running, the user must assess whether the computed response is significantly affected before using the results. This is an area where further modification to the material model may be necessary.

During the investigation of the numerical instability, other modifications to material type 45 were also identified. A term related to fractional dilatancy was missing from the calculation of the effective plastic strain increment quantity. It was also determined that there was an error in a component of the derivative that calculates the change in the current failure surface radius as a fraction of the compressive meridian with respect to anisotropy (the ratio of failure surface radius in extension and compression). The term for fractional dilatancy and the correction of the derivative component were both included in material type 45. Finally, it was determined that there was an error in calculation of the output parameter $\dot{\sigma}_{i j} \dot{\varepsilon}_{i j}^{p}$, which is only used if the output selector for epx1 is set to 4 [2]. This error was corrected, but it is believed by the authors that this option is rarely used.

\section{Material Properties and Boundary Conditions}

The structure consists of a main shear wall (the web wall), a wall perpendicular to the web wall (the flange wall), concrete slabs at each floor, a post-tensioned column that reduces torsion, and four gravity columns supporting the slabs. The floor slabs connect the web wall and the flange wall, but the connection between the walls is double-hinged. The post-tensioned column is connected to the structure by braces at each floor. The entire structure is situated on a concrete foundation that is anchored to the shake table platen. The input motion was applied along the direction parallel to the web wall. UCSD provided properties for the concrete and steel used in construction of the building.

The unit weight of the concrete is assumed to be $150 \mathrm{lbs} / \mathrm{ft}^{3}\left(0.0868 \mathrm{lbs} / \mathrm{in}^{3}\right)$, and the Poisson's ratio is assumed to be 0.2 . The compressive strength, elastic modulus and ultimate strain for the concrete determined by UCSD from test data are summarized in Table 1. A representative stress-strain curve defining these values and the concrete placement are shown in Figure 2. Note that the concrete properties for the foundation and the first 4 inches of the flange wall at floors 27 were not provided. In the previous version of the model [7], the compressive strength and elastic modulus for the concrete in the walls, the floor slabs and the foundation were averaged from $\mathrm{c} 3, \mathrm{c} 5, \mathrm{c} 7, \mathrm{c} 9, \mathrm{c} 11, \mathrm{c} 13$ and $\mathrm{c} 15\left(\mathrm{f}_{\mathrm{c}}{ }^{\prime}=5.87 \mathrm{ksi}\right.$ and $\left.\mathrm{E}_{\mathrm{c}}=4350 \mathrm{ksi}\right)$; and the compressive strength and elastic modulus for the concrete in the post-tensioned column and its foundation were averaged from $\mathrm{c} 17$ and $\mathrm{c} 18\left(\mathrm{f}_{\mathrm{c}}{ }^{\prime}=5.54 \mathrm{ksi}\right.$ and $\left.\mathrm{E}_{\mathrm{c}}=4300 \mathrm{ksi}\right)$. However, the model was changed so that each floor is represented with separate concrete properties, because the properties vary quite significantly for each floor. In order to implement this improvement to the model, the details of the rebar discretization were simplified in order to limit the total number of material definitions to a reasonable number. Since the properties for the foundation and the first 4 inches of the flange wall at floors 2-7 (concrete placements c1, c4, c6, c8, c10, c12, c14 and c16) were not provided; the concrete in those regions was assumed to have the properties of neighboring regions $(\mathrm{c} 1=\mathrm{c} 2, \mathrm{c} 4=\mathrm{c} 3, \mathrm{c} 6=\mathrm{c} 5, \mathrm{c} 8=\mathrm{c} 7, \mathrm{c} 10=\mathrm{c} 9, \mathrm{c} 12=\mathrm{c} 11, \mathrm{c} 14=\mathrm{c} 13$ and $\mathrm{c} 16=\mathrm{c} 15)$. 
Table 1. Concrete properties supplied by UCSD

\begin{tabular}{|c|c|c|c|c|c|c|c|}
\hline \multicolumn{8}{|c|}{ Concrete tabulated material properties } \\
\hline concrete placement & & $\mathrm{fc}^{\prime}$ (ksi) & Fc' avg (ksi) & Ec (ksi) & Ec avg (ksi) & $\varepsilon c u$ & $\varepsilon c u$ avg \\
\hline \multirow{2}{*}{ c2 } & specimen1 & 8.00 & \multirow{2}{*}{7.87} & 3415 & \multirow{2}{*}{3349} & -0.00291 & \multirow{2}{*}{-0.00281} \\
\hline & specimen2 & 7.74 & & 3282 & & -0.00271 & \\
\hline \multirow{2}{*}{ c3 } & specimen1 & 5.30 & \multirow{2}{*}{5.43} & 4019 & \multirow{2}{*}{3549} & -0.00244 & \multirow{2}{*}{-0.00269} \\
\hline & specimen2 & 5.56 & & 3080 & & -0.00294 & \\
\hline \multirow{2}{*}{ c5 } & specimen1 & 5.58 & \multirow{2}{*}{5.70} & 3875 & \multirow{2}{*}{3771} & -0.00202 & \multirow{2}{*}{-0.00229} \\
\hline & specimen2 & 5.81 & & 3666 & & -0.00256 & \\
\hline \multirow{2}{*}{ c7 } & specimen1 & 6.00 & \multirow{2}{*}{6.11} & 4626 & \multirow{2}{*}{5053} & -0.00237 & \multirow{2}{*}{-0.00214} \\
\hline & specimen2 & 6.22 & & 5480 & & -0.00192 & \\
\hline \multirow{2}{*}{ c9 } & specimen1 & 5.86 & \multirow{2}{*}{6.03} & 4491 & \multirow{2}{*}{4380} & -0.00212 & \multirow{2}{*}{-0.00236} \\
\hline & specimen2 & 6.21 & & 4269 & & -0.00261 & \\
\hline \multirow{2}{*}{ c11 } & specimen1 & 5.62 & \multirow{2}{*}{5.80} & 4121 & \multirow{2}{*}{4191} & -0.00214 & \multirow{2}{*}{-0.00225} \\
\hline & specimen2 & 5.99 & & 4262 & & -0.00236 & \\
\hline \multirow{2}{*}{ c13 } & specimen1 & 5.68 & \multirow{2}{*}{5.78} & 4886 & \multirow{2}{*}{4661} & -0.00226 & \multirow{2}{*}{-0.00233} \\
\hline & specimen2 & 5.88 & & 4435 & & -0.00239 & \\
\hline \multirow{2}{*}{ c15 } & specimen1 & 6.26 & \multirow{2}{*}{6.25} & 4762 & \multirow{2}{*}{4864} & -0.00209 & \multirow{2}{*}{-0.00210} \\
\hline & specimen2 & 6.23 & & 4965 & & -0.00211 & \\
\hline \multirow{2}{*}{ c17 } & specimen1 & 5.66 & 59 & 4439 & & -0.00249 & \\
\hline & specimen2 & 5.59 & 5.62 & 3949 & 4194 & -0.00220 & -0.00234 \\
\hline 18 & specimen1 & 5.40 & 545 & 4903 & 1300 & -0.00192 & \\
\hline c18 & specimen2 & 5.51 & 5.45 & 3894 & 4398 & -0.00247 & -0.00220 \\
\hline
\end{tabular}

Definition of provided material data parameters

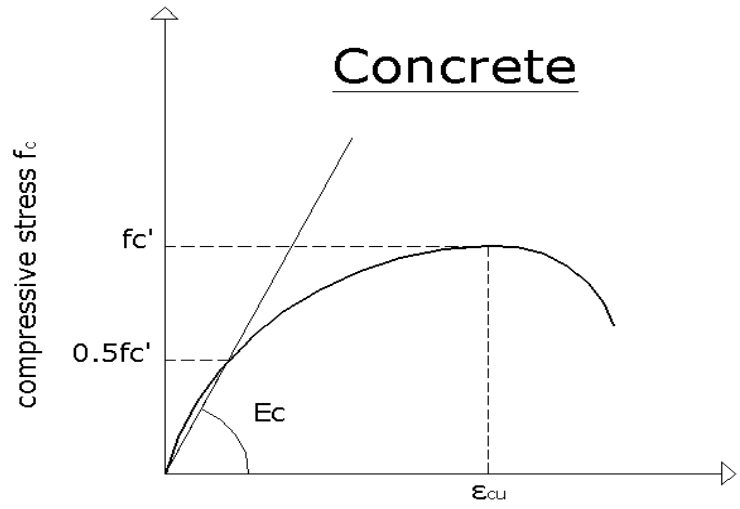

compressive strain $\varepsilon_{c}$

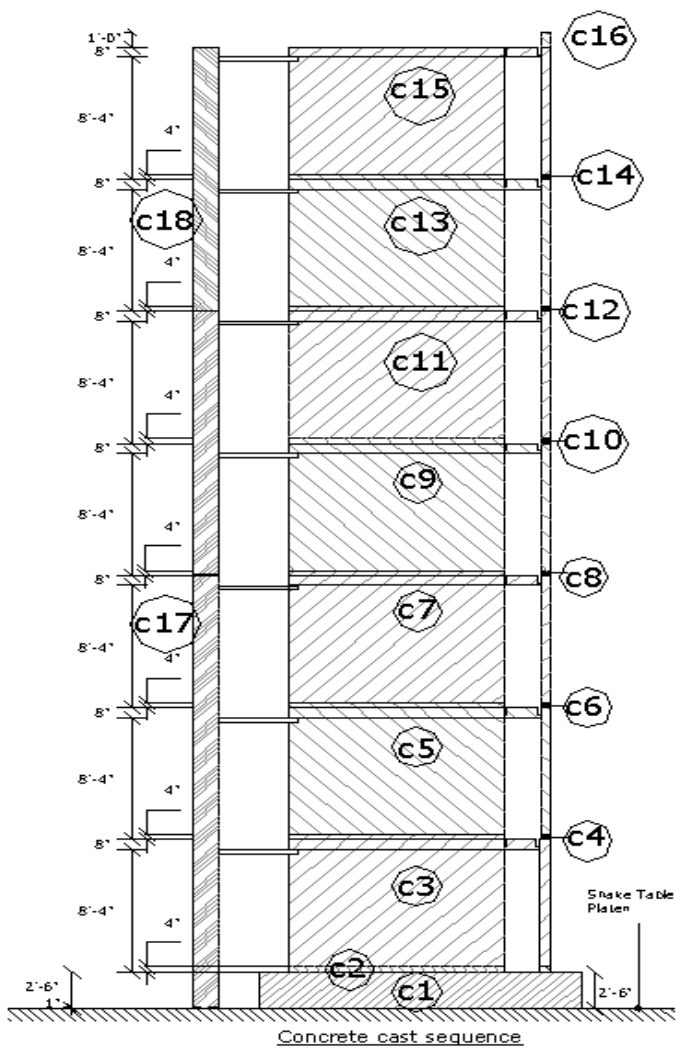

Figure 2. Representative concrete stress-strain curve for properties supplied by UCSD (left), and schematic of concrete placement locations (right) 
Stress-strain curves were also provided by UCSD for each of the concrete placements listed in Table 1. The concrete parameters were calibrated by comparing the experimental curves to the results of simulated concrete cylinder unconfined compression tests (Figure 3). The initial concrete parameters were determined for each floor by supplying the unconfined compressive strength $\left(f_{\mathrm{c}}{ }^{\prime}\right)$ from the tests as input to material type 65 [2], the version of the Kargozian \& Case concrete model with automated generation of the material properties [8]. This generates all of the necessary parameters for material types 45 and 66 . These generated parameters are used as input to the concrete cylinder unconfined compression test model, and the computed responses are compared to the experimentally obtained curves (Figure 4 through Figure 13). In each figure, there are four experimentally measured curves (two specimens and 2 strain gauges for each specimen). There is noticeable measurement noise/error in some of the curves for $\mathrm{c} 3$ and c18 at low strain. For c7, c9, c11, c13, c15, c17 and c18, the automatically generated parameters yield a good fit of the experimental data. However, for $\mathrm{c} 2, \mathrm{c} 3$ and $\mathrm{c} 5$, the generated parameters yield concrete that is initially too stiff, especially for c2. Thus, for those three sets the bulk modulus and unloading bulk modulus were reduced manually in order to obtain a better fit of the initial stiffness. The curves labeled "generated model" show the responses with generated parameters, and the curves labeled "modified model" show the responses with the manually modified parameters. The "lambda stretch" factor, which has an effect on rate dependence, is set to $s=50$ for the simulations [2]. This does not have an effect for the unconfined compression test simulations because rate effects are neglected, but the value is chosen for the seismic simulations to provide a moderate amount of increased strength with increasing rate.

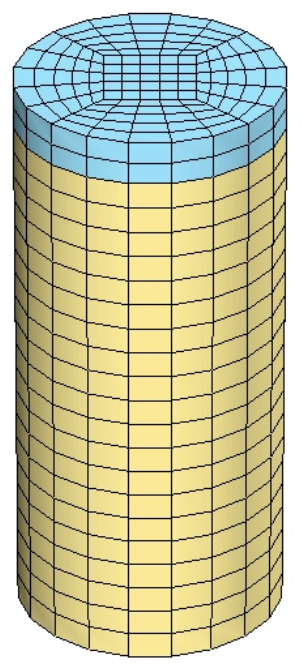

Figure 3. Finite element model of concrete cylinder for unconfined compression test 


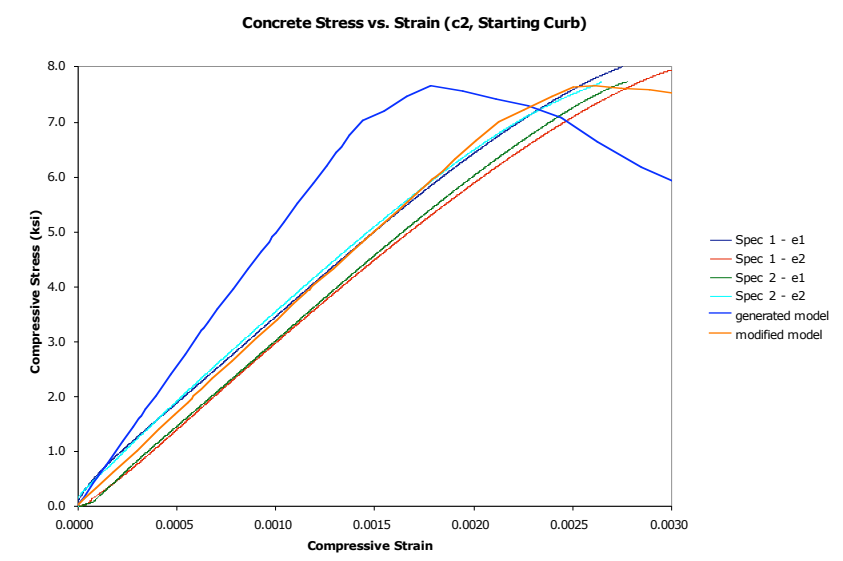

Figure 4. Simulated stress-strain curves compared to experimentally measured curves of concrete cylinder unconfined compression tests for $c 2$ concrete placement

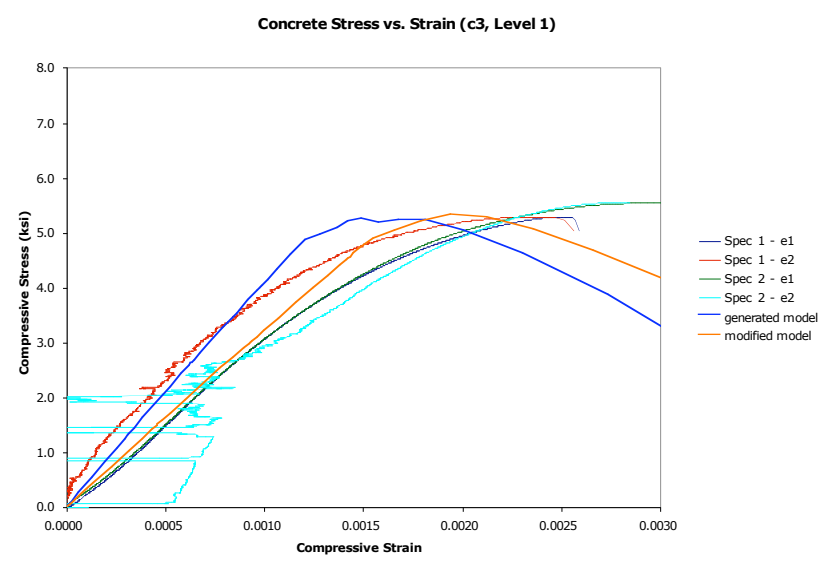

Figure 5. Simulated stress-strain curves compared to experimentally measured curves of concrete cylinder unconfined compression tests for $\mathbf{c} 3$ concrete placement

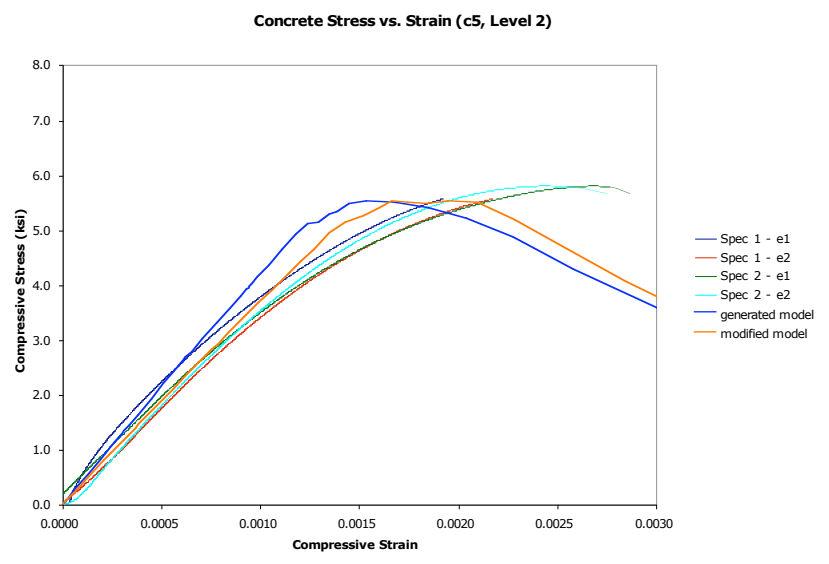

Figure 6. Simulated stress-strain curves compared to experimentally measured curves of concrete cylinder unconfined compression tests for $\mathbf{c} 5$ concrete placement 


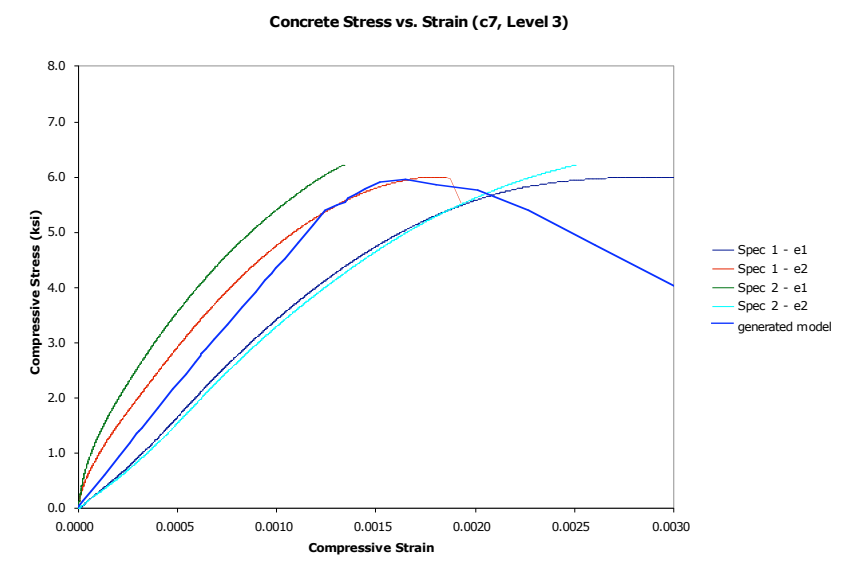

Figure 7. Simulated stress-strain curve compared to experimentally measured curves of concrete cylinder unconfined compression tests for 7 concrete placement

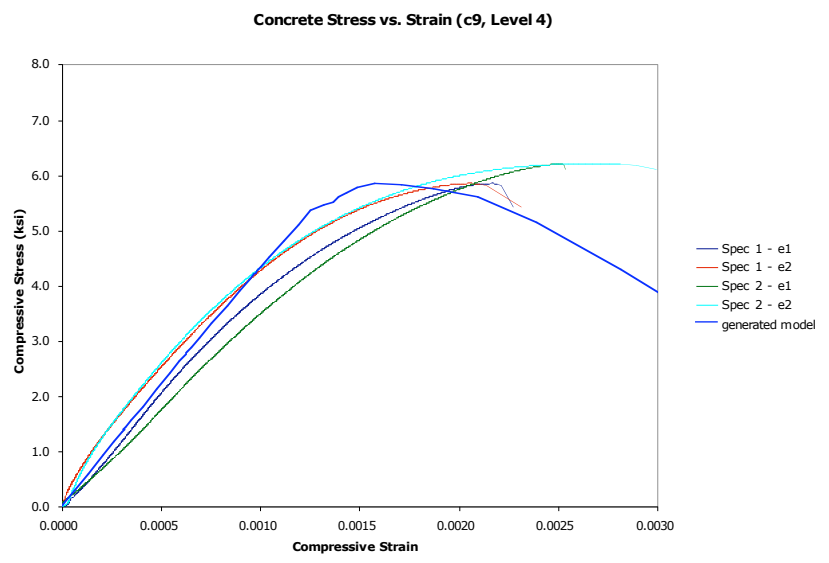

Figure 8. Simulated stress-strain curve compared to experimentally measured curves of concrete cylinder unconfined compression tests for $\mathrm{c} 9$ concrete placement

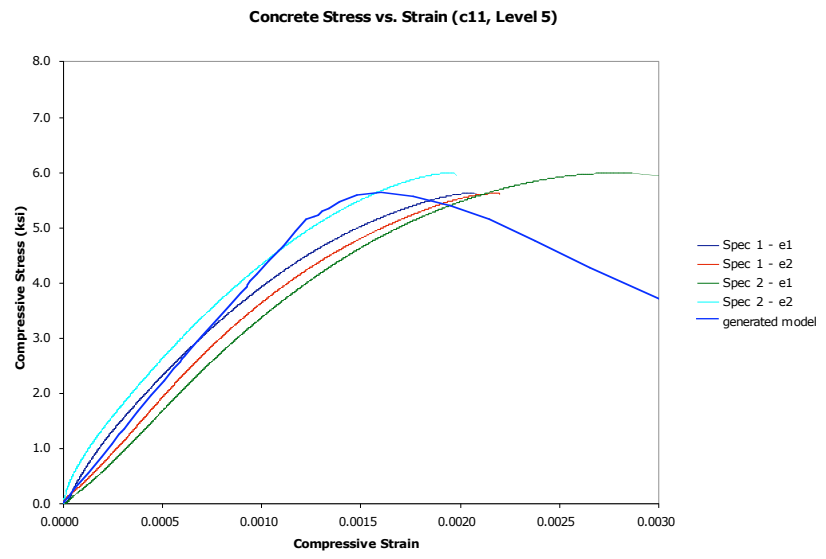

Figure 9. Simulated stress-strain curve compared to experimentally measured curves of concrete cylinder unconfined compression tests for c11 concrete placement 


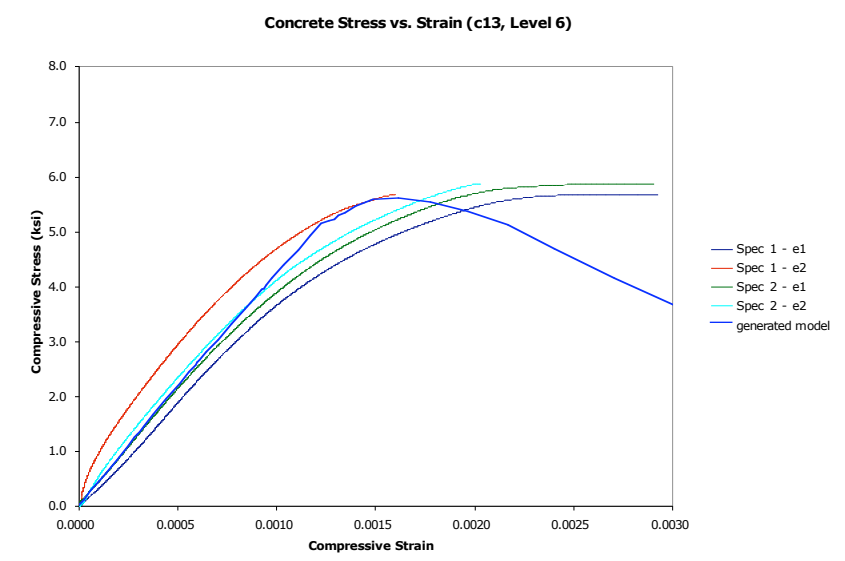

Figure 10. Simulated stress-strain curve compared to experimentally measured curves of concrete cylinder unconfined compression tests for c13 concrete placement

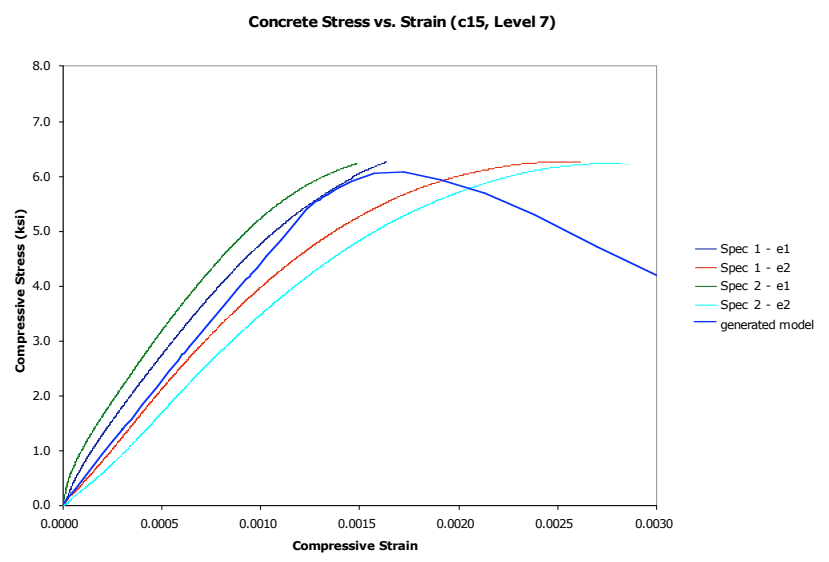

Figure 11. Simulated stress-strain curve compared to experimentally measured curves of concrete cylinder unconfined compression tests for c15 concrete placement

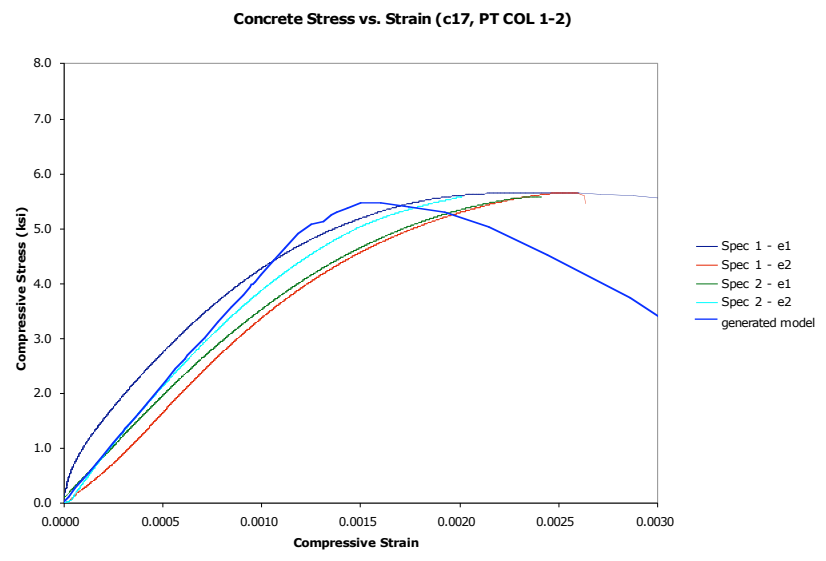

Figure 12. Simulated stress-strain curve compared to experimentally measured curves of concrete cylinder unconfined compression tests for c17 concrete placement 


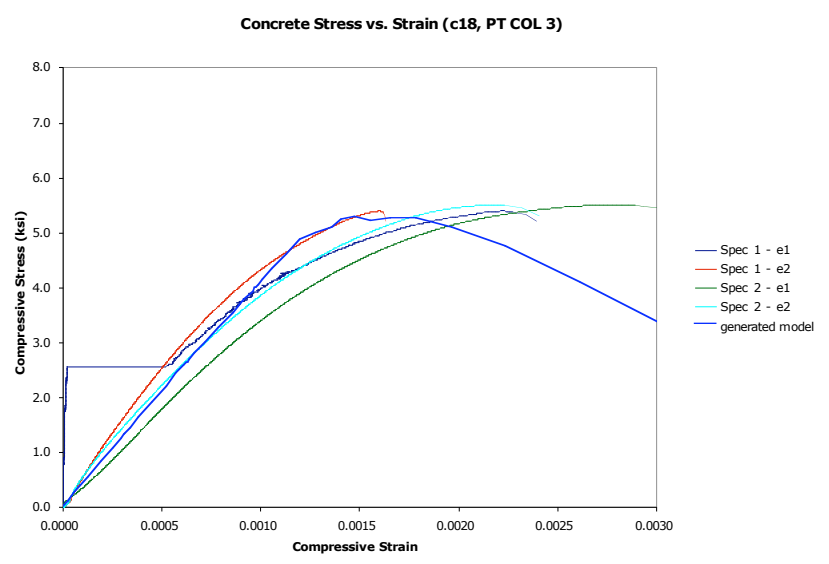

Figure 13. Simulated stress-strain curve compared to experimentally measured curves of concrete cylinder unconfined compression tests for c18 concrete placement

In addition to the nonlinear analyses, linear analyses have also been performed for the structure. For these analyses, the elastic modulus of each concrete placement was estimated from the data illustrated in Figure 4 through Figure 13 using the convention shown in Figure 2. The elastic moduli are summarized in Table 2. Notice that these values are generally lower than those provided by UCSD (Table 1). It is not known why the values differ, so the moduli computed directly from the experimental data (Table 2) were used.

Table 2. Elastic moduli for linear analyses

\begin{tabular}{|c|c|}
\hline Concrete Placement & Elastic Modulus (ksi) \\
\hline c2 & 3230 \\
\hline c3 & 3320 \\
\hline c5 & 3760 \\
\hline c7 & 4460 \\
\hline c1 11 & 4300 \\
\hline c13 & 4100 \\
\hline c15 & 4490 \\
\hline c17 & 4630 \\
\hline c18 & 4080 \\
\hline \multicolumn{2}{|c}{} \\
\hline
\end{tabular}

The yield strength, ultimate strength, yield strain and ultimate strain provided by UCSD for the rebar placements are summarized in Table 3, and a representative stress-strain curve defining these values is shown in Figure 14. The yield strength, ultimate strength and ultimate strain for all rebar in the finite element model are assumed to be $\mathrm{f}_{\mathrm{y}}=65 \mathrm{ksi}, \mathrm{f}_{\mathrm{su}}=105 \mathrm{ksi}, \varepsilon_{\mathrm{su}}=0.107$, respectively. These are based primarily from the values for $b 1, b 2$ and $b 3$, which are the most prominent bars in the lower walls and slabs. The unit weight of the rebar steel is assumed to be $0.283 \mathrm{lbs} / \mathrm{in}^{3}$, and the Poisson's ratio is assumed to be 0.29 . The elastic modulus of the rebar steel is assumed to be $29 \times 10^{6} \mathrm{psi}$. 
Table 3. Rebar properties supplied by UCSD

\begin{tabular}{|c|c|c|c|c|c|}
\hline \multicolumn{6}{|c|}{ Reinforcing Steel tabulated meterial properties } \\
\hline bar name & & fy (ksi) & fsu (ksi) & $\varepsilon s h$ & $\varepsilon s u$ \\
\hline \multirow{4}{*}{ b1 } & spec1 & 65.2 & 108.6 & 0.0060 & 0.0988 \\
\hline & spec2 & 64.8 & 109.0 & - & 0.1034 \\
\hline & spec3 & 65.7 & 109.2 & 0.0047 & 0.1004 \\
\hline & avg & 65.2 & 108.9 & 0.0054 & 0.1009 \\
\hline \multirow{4}{*}{ b2 } & spec1 & 63.4 & 103.2 & 0.0081 & 0.1121 \\
\hline & spec2 & 62.9 & 102.9 & 0.0072 & 0.1090 \\
\hline & spec3 & 63.1 & 103.0 & 0.0069 & 0.1077 \\
\hline & avg & 63.1 & 103.0 & 0.0074 & 0.1096 \\
\hline \multirow{4}{*}{ b3 } & spec1 & 66.1 & 101.0 & 0.0075 & 0.1158 \\
\hline & spec2 & 65.6 & 101.0 & 0.0081 & 0.1098 \\
\hline & spec3 & - & - & - & - \\
\hline & avg & 65.9 & 101.0 & 0.0078 & 0.1128 \\
\hline \multirow{4}{*}{ b4 } & spec1 & 69.3 & 111.1 & 0.0074 & 0.1158 \\
\hline & spec2 & 68.9 & 111.1 & 0.0083 & 0.1075 \\
\hline & spec3 & - & - & - & - \\
\hline & avg & 69.1 & 111.1 & 0.0079 & 0.1117 \\
\hline \multirow{4}{*}{ b5 } & spec1 & 65.7 & 112.6 & 0.0071 & 0.1077 \\
\hline & spec2 & 65.6 & 112.4 & 0.0068 & 0.1028 \\
\hline & spec3 & - & - & - & - \\
\hline & avg & 65.7 & 112.5 & 0.0070 & 0.1053 \\
\hline \multirow{4}{*}{ b6 } & spec1 & 71.4 & 114.0 & 0.0057 & 0.1001 \\
\hline & spec2 & 71.7 & 113.6 & 0.0053 & 0.1060 \\
\hline & spec3 & 71.6 & 113.6 & 0.0046 & 0.1079 \\
\hline & avg & 71.6 & 113.7 & 0.0052 & 0.1046 \\
\hline \multirow{4}{*}{ b7 } & spec1 & 66.5 & 98.0 & 0.0061 & 0.0406 \\
\hline & spec2 & 65.6 & 107.5 & 0.0052 & 0.1064 \\
\hline & spec3 & 67.0 & 107.7 & 0.0049 & 0.1039 \\
\hline & avg & 66.4 & 104.4 & 0.0054 & 0.0836 \\
\hline \multirow{4}{*}{ b8 } & spec1 & 66.3 & 105.2 & 0.0091 & 0.1146 \\
\hline & spec2 & 66.0 & 105.2 & 0.0086 & 0.1224 \\
\hline & spec3 & 65.7 & 105.0 & 0.0080 & 0.1136 \\
\hline & avg & 66.0 & 105.1 & 0.0086 & 0.1169 \\
\hline \multirow{4}{*}{ b9 } & spec1 & 63.7 & 102.5 & 0.0090 & 0.1154 \\
\hline & spec2 & 62.9 & 101.8 & 0.0078 & 0.1102 \\
\hline & spec3 & 64.0 & 102.1 & 0.0094 & 0.1036 \\
\hline & avg & 63.5 & 102.1 & 0.0087 & 0.1098 \\
\hline \multirow{4}{*}{ b10 } & spec1 & 60.3 & 98.4 & - & 0.0889 \\
\hline & spec2 & 66.3 & 108.5 & - & 0.0941 \\
\hline & spec3 & 66.5 & 108.8 & - & 0.0903 \\
\hline & avg & 64.4 & 105.2 & - & 0.0911 \\
\hline \multirow{4}{*}{ b11 } & spec1 & 71.0 & 109.9 & 0.0052 & 0.0905 \\
\hline & spec2 & 70.9 & 109.4 & 0.0053 & 0.0952 \\
\hline & spec3 & 70.9 & 107.0 & 0.0055 & 0.0545 \\
\hline & avg & 70.9 & 108.7 & 0.0053 & 0.0800 \\
\hline
\end{tabular}




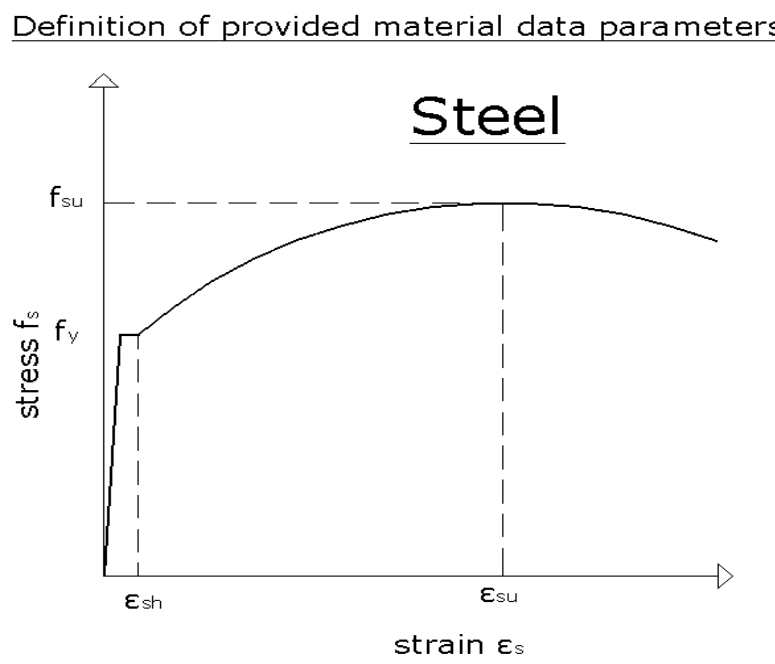

Figure 14. Representative steel stress-strain curve for properties supplied by UCSD

The gravity columns (Figure 15) consist of high-strength Dywidag Threadbar rods that are embedded in 4" diameter steel pipe with grout between the rod and the pipe. The Dywidag Threadbar rods have an elastic modulus of $29.7 \times 10^{6}$ psi. At levels $1-3$, the columns are 1.75 " diameter rod and Extra Strong steel pipe; and at levels 4-7, the columns are 1.375" diameter rod and Standard steel pipe. There were ball joints at both ends. The gravity columns were designed to remain elastic, so they are modeled elastically in the finite element analyses.

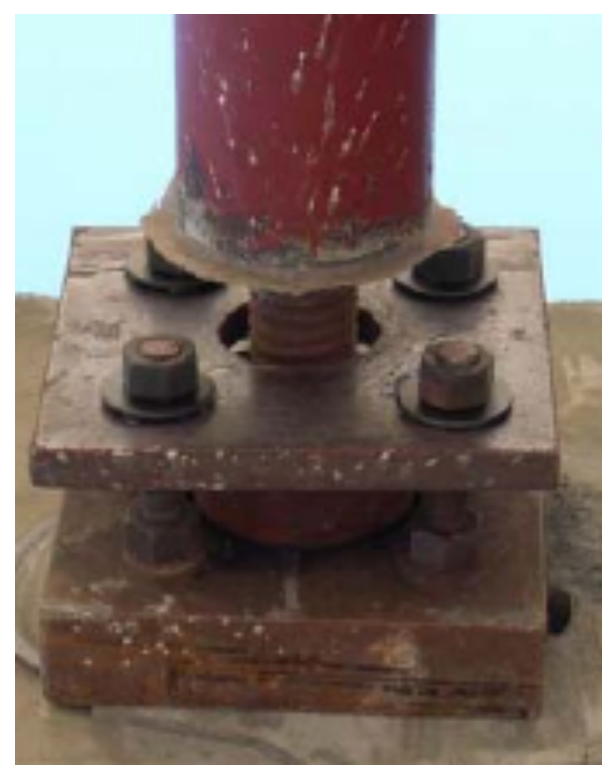

Figure 15. End connection of a gravity column

The braces connecting the post-tensioned column to the structure (Figure 16) are L-section

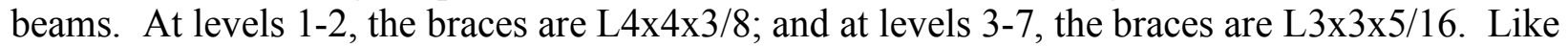
the gravity columns, the braces were designed to remain elastic, so they are modeled elastically. The same standard steel properties used for the rebar are also assumed for the braces. 


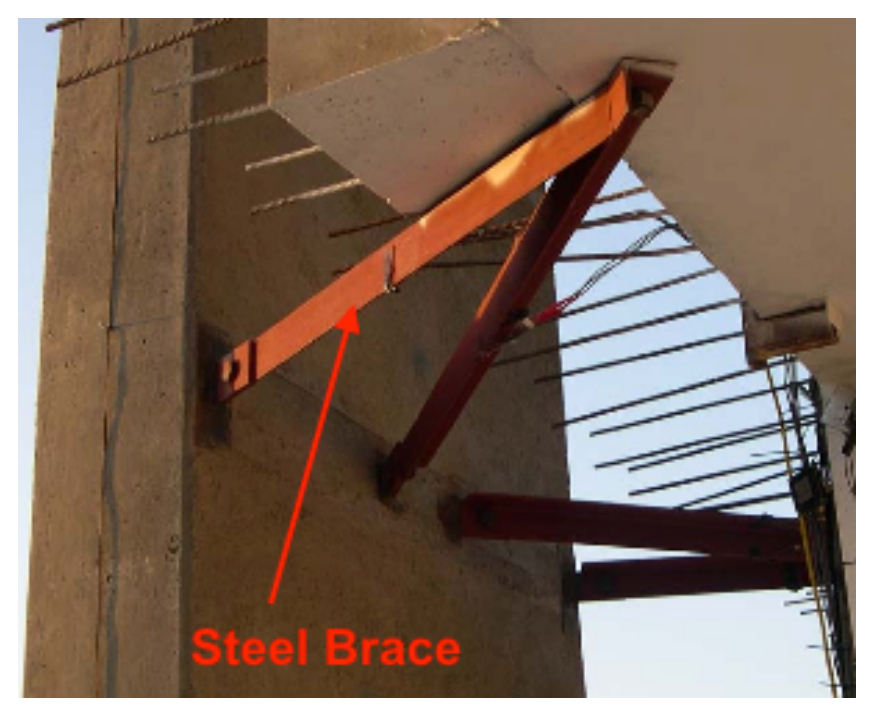

Figure 16. Braces connecting the post-tensioned column to a floor slab

The post-tensioned column was post-tensioned with two 1.25" diameter high-strength Dywidag rods. The force in each rod was 110 kips. The column was designed to rock at its base in the direction of the ground motion. This was accomplished by including a hinge at the base of the foundation for the column.

In the previous version of the model [7], the shake table platen was not included. However, it is believed that the rotational flexibility of the table is an important contributor to the overall response. Therefore, the table platen was added to the finite element model as a rigid shell, weighing 506 kips, with beams acting as springs at both ends of the platen (Figure 17). The beams are calibrated to provide a rotational stiffness of the table in the direction of the earthquake excitation about a pivot point directly below the center of the web wall. An estimate of the rotational stiffness of the table platen during each earthquake was provided by UCSD. An estimate of the rotational stiffness of the combined platen and foundation was also provided. The stiffnesses were estimated from motions recorded during the earthquakes and based on the instant of time of the maximum moment. The stiffnesses were estimated separately for displacement in both directions: relative displacement towards east (flange wall side) and relative displacement towards west (post-tensioned column side). The estimates provided by UCSD are presented in Table 4. Note that while the foundation is included in the finite element model, the rotational flexibility of the foundation is not completely modeled because the actual foundation was not rigidly attached to the platen as it is in the model (slide surface type 8 , nodes spotwelded to surface [2]). The finite element model was calibrated for 4 different rotational stiffnesses: $0.5 \times 10^{7} \mathrm{kip}-\mathrm{ft} / \mathrm{rad}, 1.0 \times 10^{7} \mathrm{kip}-\mathrm{ft} / \mathrm{rad}, 2.0 \times 10^{7} \mathrm{kip}-\mathrm{ft} / \mathrm{rad}$, and $3.5 \times 10^{7} \mathrm{kip}-\mathrm{ft} / \mathrm{rad}$. In the model, the stiffness is the same for both directions. A version of the model with the table platen removed was also used for comparison. 


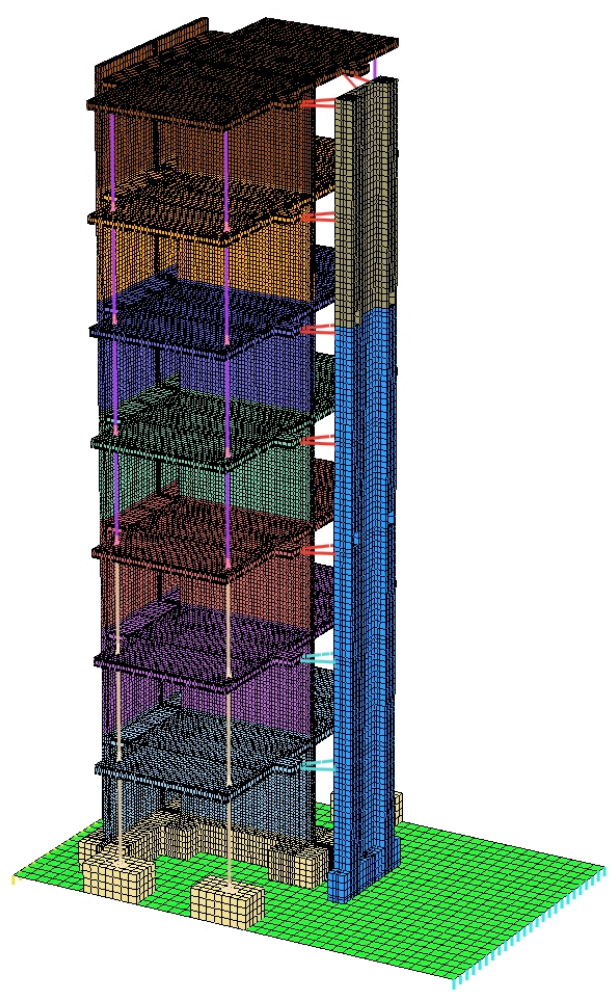

Figure 17. Finite element model of the 7-story structure situated on the shake table platen modeled as a rigid shell with springs at both ends of the platen

Table 4. Estimates of rotational flexibility for the shake table and the foundation/shake table provided by UCSD

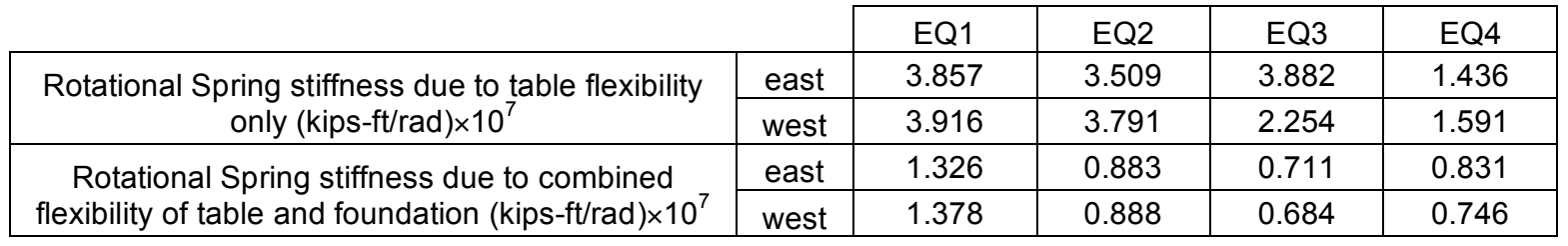

The input ground motions were provided by UCSD as accelerations that were measured at the top of the foundation. Before using these raw acceleration records as input to the finite element model, the mean was removed from a $60-\mathrm{sec}$ section of the record. The acceleration histories for each of the four earthquakes are shown in Figure 18. In order to include the flexibility from the foundation and the shake table platen in the simulations, the ground acceleration was applied to the shake table platen and foundation base along the pivot point directly below the center of the web wall. The rationale is that while the motion is not identical at the top and the base of the foundation, it is very similar. For the model with the table platen removed, the ground acceleration was applied at the base of the foundation. 

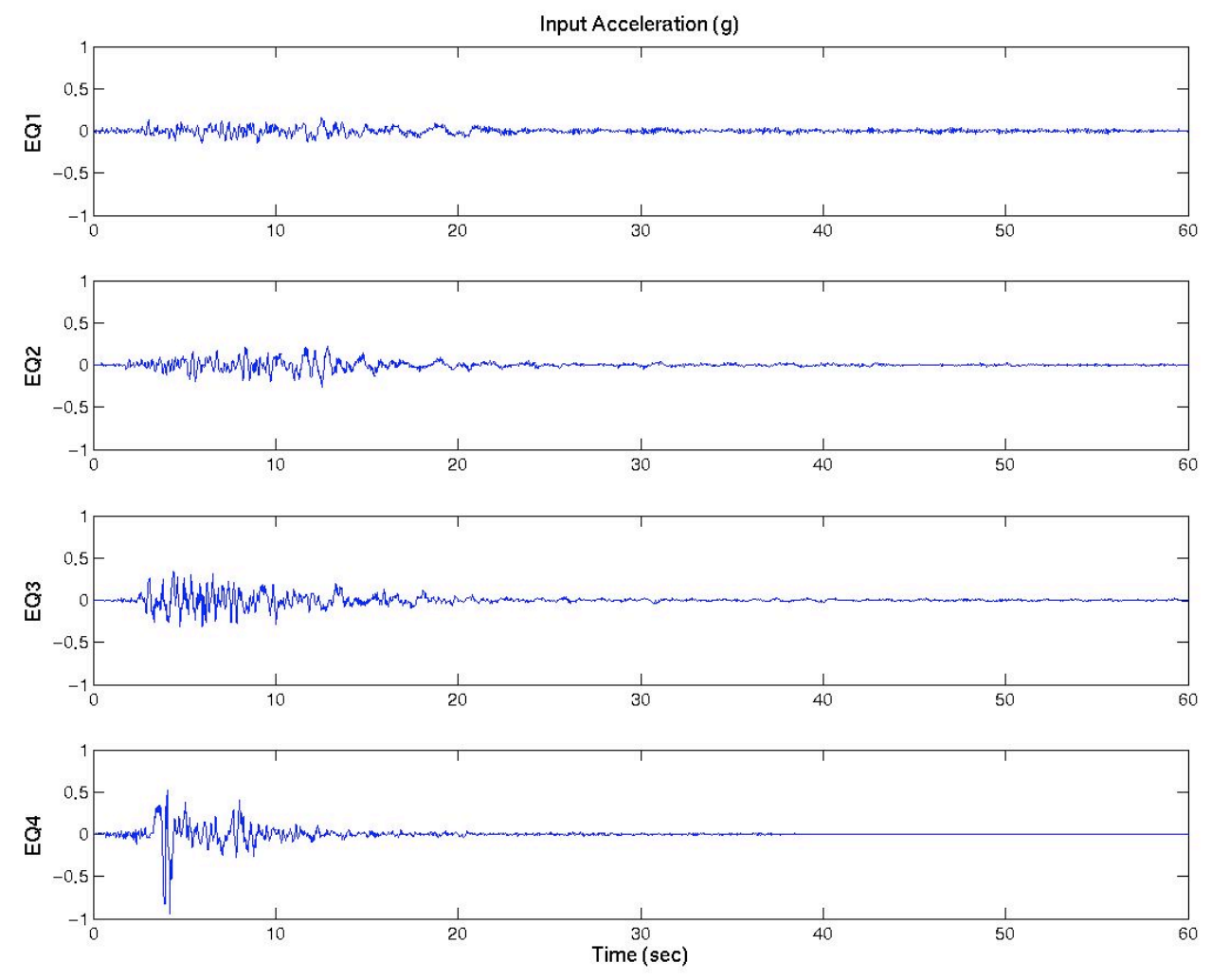

Figure 18. Acceleration time histories for the four earthquakes

Other modeling assumptions are summarized below:

- The ends of the gravity columns and the braces are modeled as fixed, as opposed to pinned. In the actual structure, the gravity columns had ball joints at both ends and the braces would most accurately be described as pinned about one axis and fixed about the other two axes at both ends. However, both the braces and columns are modeled as fixed at the ends to reduce the effects from stress concentrations and minimize the contribution to hourglass modes. The significance of this is expected to be small for the overall behavior of the structure when subjected to a seismic input.

- There was slackness at the connections of the gravity columns $(0.08$ inches at levels $1-3$ and 0.4 inches at levels 4-7) that had to be overcome before the columns could take tension. This slackness is neglected in the model. Again, the significance of this is expected to be small for the overall behavior of the structure when subjected to a seismic input.

- The sections of the gravity columns that were embedded in steel pipe and grout are modeled as beams that carry axial loads as if they were only the Dywidag Threadbar rod, but the entire composite beam carries bending loads. The rationale is that the axial load could not be transmitted from the rod to the grout to a significant degree.

- Before the structure was subjected to the fourth earthquake motion in the experiment, the connection between the bracing and the first level slab was slotted in the direction of motion. Also, the steel braces at all levels were replaced with beams of larger cross 
section and the connections were improved to remove slackness. The details of the new beams were not provided by UCSD. The slotting and the slackness in the connections are neglected in the model, because the overall behavior of the structure when subjected to a seismic input is not expected to be affected significantly. The modification of the braces is also neglected in the model, because the details were not provided and the significance is expected to be small anyway.

- The post-tensioned column was fabricated as three precast pieces. No reinforcement crossed the joints between the pieces. In the model, the homogenized rebar is spread out over the entire height of the column and no gap in the rebar is modeled. The posttensioned column is expected to have a mostly linear elastic response, so this assumption is not expected to affect the response of the rest of the structure significantly.

- There was a protection system employing guy wires attached to the structure and anchored to the ground that would pull the structure away from the control building in the event of a collapse. The effect of these wires is insignificant because the stiffness/mass of the wires is small compared to the stiffness/mass of the structure, so the wires are neglected in the finite element model.

\section{Linear Analyses}

\subsection{Linear Static/Eigen Analyses}

Linear finite element models (Figure 19) of the structure were generated, in which linear properties were assumed for the concrete (see Table 2 for elastic moduli) and rebar was not modeled. With gravity applied to the structure and the pressure from the post-tensioned rods applied at the top and the base of the column, static analyses were run in NIKE3D [9] for five variations of the model: no shake table platen and four shake table platen rotational stiffnesses. The natural frequencies and mode shapes of the structure were determined from eigen-analyses of the models. The first torsional mode, the first longitudinal mode and the second longitudinal mode for each of the model variations are summarized in Table 5. These mode shapes are shown in Figure 20 and Figure 21 for the models with a table platen rotational stiffness of $0.5 \times 10^{7}$ kip$\mathrm{ft} / \mathrm{rad}$ and with no table platen, respectively. In the previous version of the model with averaged concrete properties and no table platen [7], natural frequencies of $2.17 \mathrm{~Hz}$ and $2.65 \mathrm{~Hz}$ were computed for the first torsional and first longitudinal modes, respectively. The natural frequency for the second longitudinal mode of that model is $11.47 \mathrm{~Hz}$. Note that the first longitudinal mode should be the dominant mode of the earthquake response since the building is excited uniaxially in the direction of motion for the longitudinal modes. 

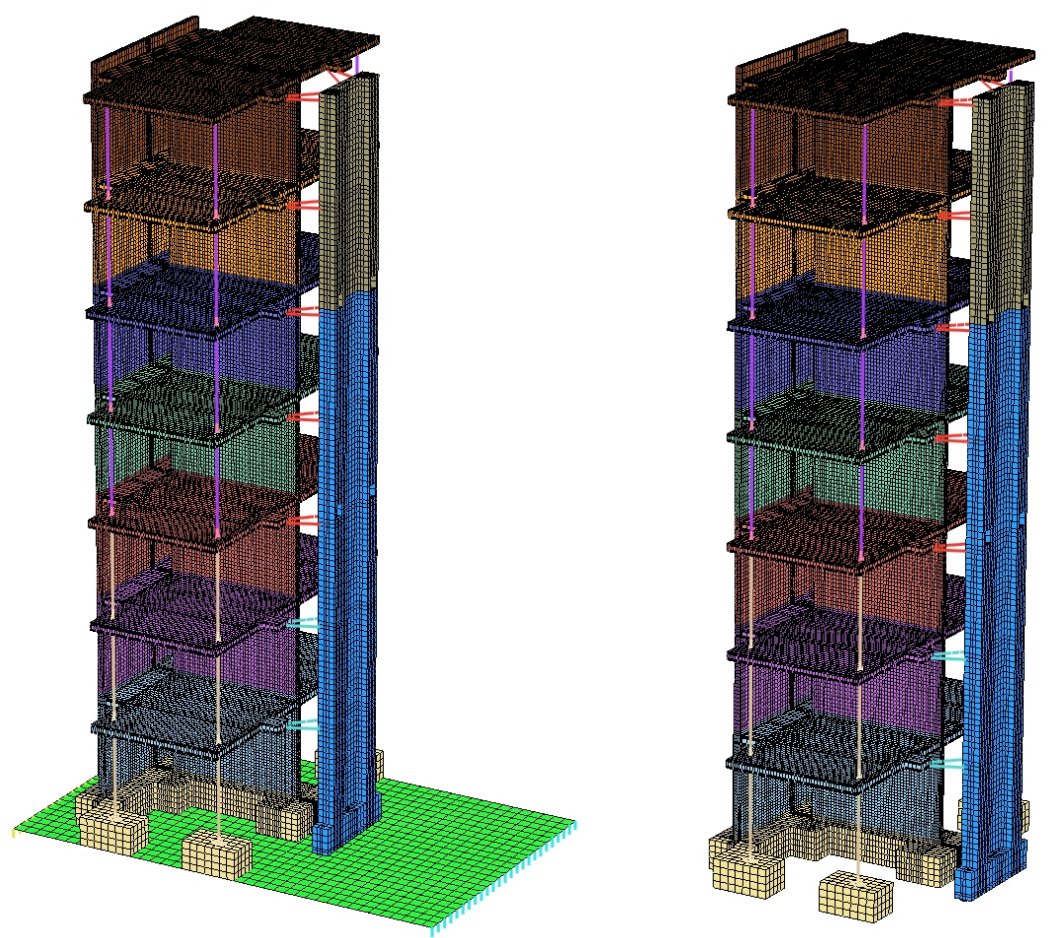

Figure 19. Linear finite element models for NIKE3D analyses with shake table platen (left) and without shake table platen (right)

Table 5. Natural frequencies of the first torsional, first longitudinal and second longitudinal modes

\begin{tabular}{|c|c|c|c|}
\hline $\begin{array}{c}\text { Rotational } \\
\text { Stiffness of Shake } \\
\text { Table Platen }\end{array}$ & $\begin{array}{c}\text { First } \\
\text { Torsional } \\
\text { Mode }\end{array}$ & $\begin{array}{c}\text { First } \\
\text { Longitudinal } \\
\text { Mode }\end{array}$ & $\begin{array}{c}\text { Second } \\
\text { Longitudinal } \\
\text { Mode }\end{array}$ \\
\hline $0.5 \times 10^{7} \mathrm{kip}-\mathrm{ft} / \mathrm{rad}$ & $2.00 \mathrm{~Hz}$ & $1.97 \mathrm{~Hz}$ & $9.38 \mathrm{~Hz}$ \\
\hline $1.0 \times 10^{7} \mathrm{kip}-\mathrm{ft} / \mathrm{rad}$ & $2.00 \mathrm{~Hz}$ & $2.20 \mathrm{~Hz}$ & $10.29 \mathrm{~Hz}$ \\
\hline $2.0 \times 10^{7} \mathrm{kip}-\mathrm{ft} / \mathrm{rad}$ & $2.00 \mathrm{~Hz}$ & $2.33 \mathrm{~Hz}$ & $10.68 \mathrm{~Hz}$ \\
\hline $3.5 \times 10^{7} \mathrm{kip}-\mathrm{ft} / \mathrm{rad}$ & $2.00 \mathrm{~Hz}$ & $2.40 \mathrm{~Hz}$ & $10.82 \mathrm{~Hz}$ \\
\hline No Table & $2.12 \mathrm{~Hz}$ & $2.51 \mathrm{~Hz}$ & $11.03 \mathrm{~Hz}$ \\
\hline
\end{tabular}



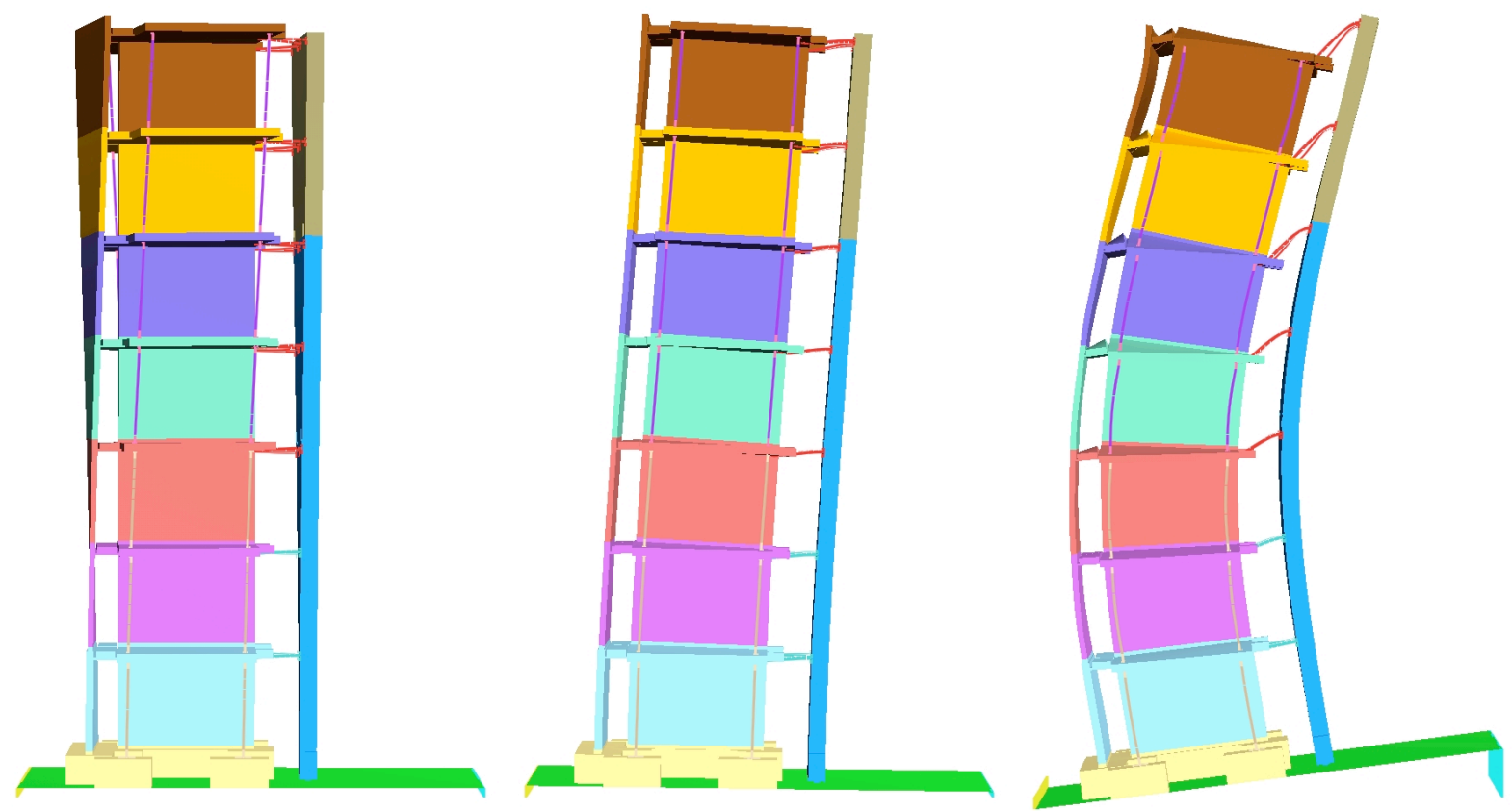

Figure 20. First torsional mode (left), first longitudinal mode (middle), and second longitudinal mode (right) for the model with a table platen rotational stiffness of $0.5 \times 10^{7}$ kip-ft/rad
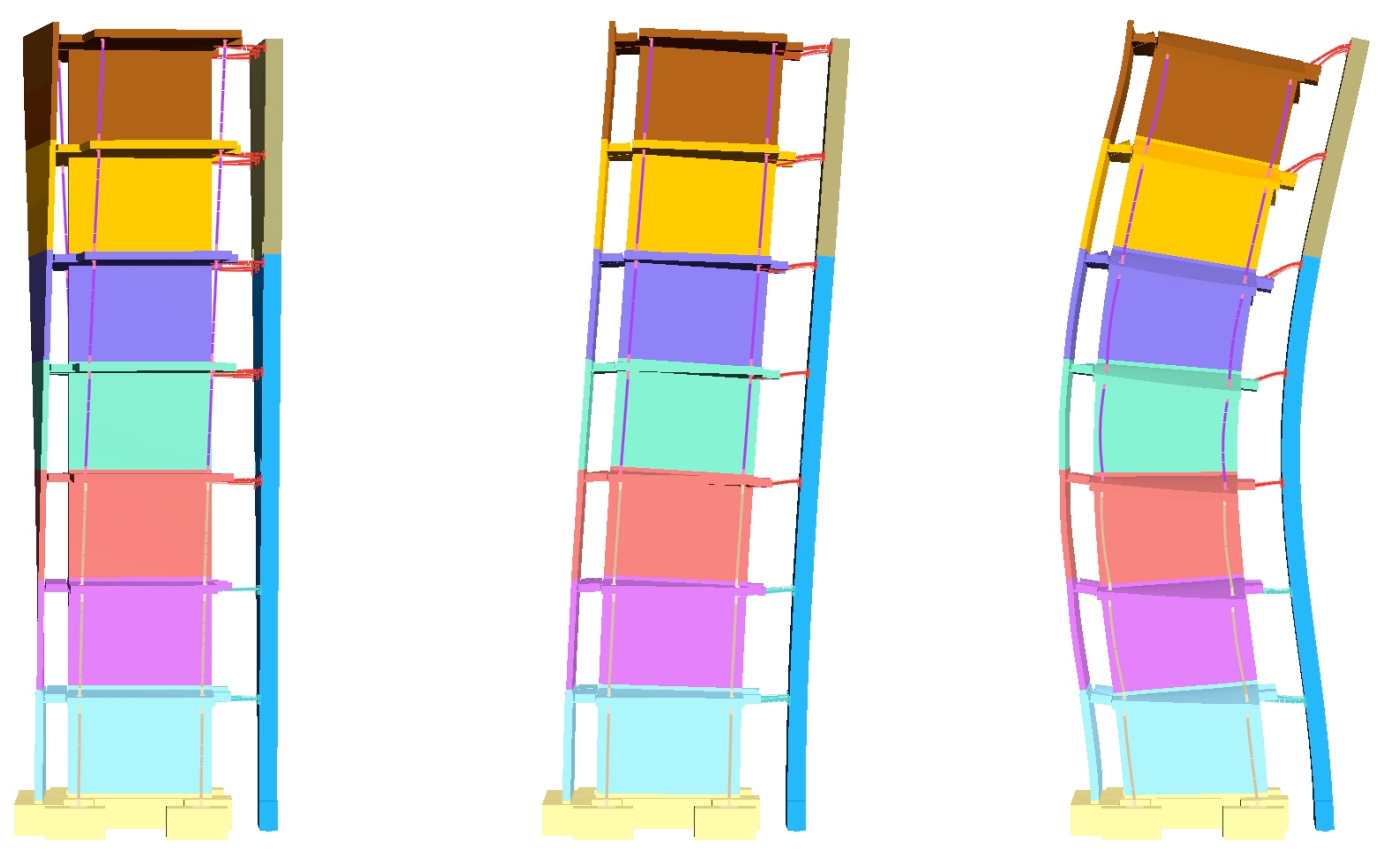

Figure 21. First torsional mode (left), first longitudinal mode (middle), and second longitudinal mode (right) for the model with no table platen

The previous version of the model with averaged properties and no table platen was globally stiffer than the current version of the model with different concrete properties for each level. It 
was observed that the previous version of the model computed a response that was too stiff [7], so the current model with better material property resolution is an improvement. However, the change in stiffness is small unless rotational stiffness of the shake table platen is also included in the model. Varying the rotational stiffness of the table platen does not have an effect on the first torsional mode, which is reasonable since rotation of the platen does not provide flexibility for torsion of the structure. Decreasing the rotational stiffness of the table decreases the frequencies of the longitudinal modes, which is also reasonable since rotation of the table platen contributes significantly to the motion of the longitudinal modes. With a rotational stiffness of $3.5 \times 10^{7}$ kip$\mathrm{ft} / \mathrm{rad}$, the change from no table rotation is relatively small. That stiffness is near the upper end of the rotational stiffnesses estimated by UCSD due to table flexibility only (Table 4). With a rotational stiffness of $0.5 \times 10^{7} \mathrm{kip}-\mathrm{ft} / \mathrm{rad}$, the change from no table rotation is quite large. That stiffness is a lower bound for the rotational stiffnesses estimated by UCSD due to table and foundation flexibility (Table 4). As is also explained in Section 3, accounting for some of the foundation flexibility through the rotational stiffness in the model is appropriate since the actual foundation is not rigidly attached to the table platen as in the model.

\subsection{Linear Dynamic Analyses}

The same finite element model that was created for the NIKE3D static/eigen-analyses was also used for linear dynamic analyses in ParaDyn [3]. However, it was modified to have a plane of symmetry (Figure 22 shows the model with the table platen) for computational efficiency, since the earthquake loading in one direction will not excite torsional modes of a symmetric structure. Mass proportional damping is used to attain $2 \%$ of critical damping at approximately $2.0 \mathrm{~Hz}$. Linear analyses were performed for all five table platen variations with all four earthquake ground motions. Gravity initialization analyses were performed and the final states were supplied as a stress initialization to the earthquake simulations. During the gravity initialization, boundary conditions were also applied to the post-tensioned column in the form of a pressure at both ends. 


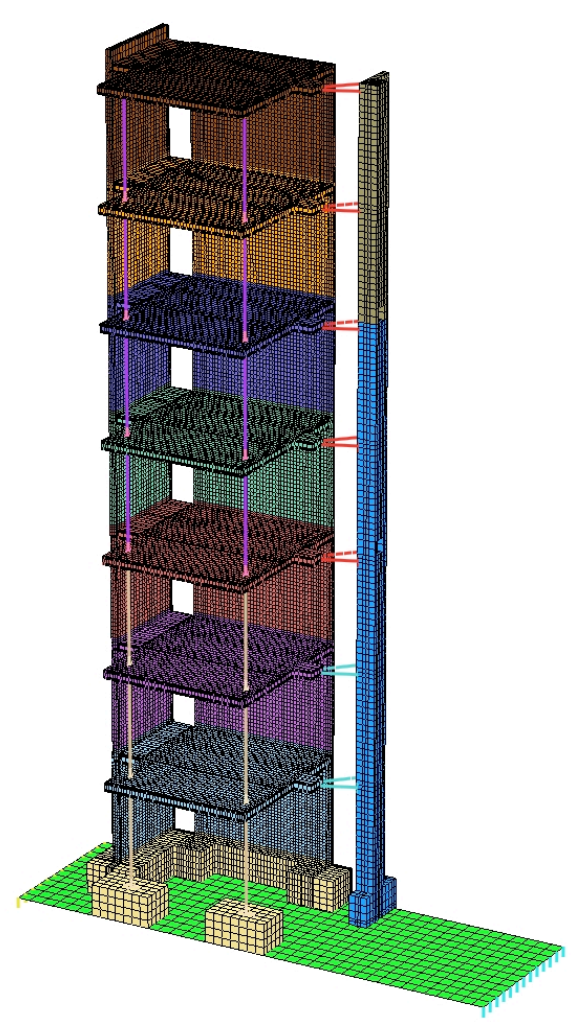

\section{Figure 22. Finite element model of the structure with the shake table platen for linear dynamic simulations in ParaDyn}

The peak roof displacement computed in each of the linear simulations is compared to the measured roof displacement for each earthquake ground motion in Table 6. The linear simulations underestimate the measured responses. The simulations are the closest to the measured peak displacement during the first earthquake, and then underestimate the peaks by almost a factor of two or more for the other three earthquakes. This makes sense because the structure can most reasonably be approximated as linear for the smallest excitation before it is damaged by ground motions with successively increasing amplitude. However, the simulated responses do not agree well with the measured response even for the first earthquake. Figure 23 shows that the actual structure had a lower period than all versions of the finite element model. This indicates that modeling the nonlinear behavior of concrete is important even for the smallest earthquake input. The progression of damage causing an even larger discrepancy between the measured response and the simulated linear responses for successive events is illustrated in Figure 24. While the model with a table platen rotational stiffness of $0.5 \times 10^{7} \mathrm{kip}-\mathrm{ft} / \mathrm{rad}$ does not compute peak displacements that are the closest to the measured values, that model does provide the responses with the frequency content that is closest to the frequency content of the measured response. The obvious reason for this is that the model with a table platen rotational stiffness of $0.5 \times 10^{7} \mathrm{kip}-\mathrm{ft} / \mathrm{rad}$ is the least stiff of the finite element models. 
Table 6. Peak values of the simulated (linear model) and measured roof displacements for four earthquake ground motions

\begin{tabular}{|c|c|c|c|c|}
\hline $\begin{array}{c}\text { Rotational } \\
\text { Stiffness of Shake } \\
\text { Table Platen }\end{array}$ & EQ1 & EQ2 & EQ3 & EQ4 \\
\hline $0.5 \times 10^{7} \mathrm{kip}-\mathrm{ft} / \mathrm{rad}$ & $1.30 \mathrm{in}$ & $2.42 \mathrm{in}$ & $2.55 \mathrm{in}$ & $6.64 \mathrm{in}$ \\
\hline $1.0 \times 10^{7} \mathrm{kip}-\mathrm{ft} / \mathrm{rad}$ & $1.29 \mathrm{in}$ & $2.67 \mathrm{in}$ & $4.05 \mathrm{in}$ & $6.41 \mathrm{in}$ \\
\hline $2.0 \times 10^{7} \mathrm{kip}-\mathrm{ft} / \mathrm{rad}$ & $1.49 \mathrm{in}$ & $2.71 \mathrm{in}$ & $3.66 \mathrm{in}$ & $6.45 \mathrm{in}$ \\
\hline $3.5 \times 10^{7} \mathrm{kip}-\mathrm{ft} / \mathrm{rad}$ & $1.56 \mathrm{in}$ & $2.87 \mathrm{in}$ & $3.47 \mathrm{in}$ & $6.40 \mathrm{in}$ \\
\hline No Table & $1.44 \mathrm{in}$ & $2.49 \mathrm{in}$ & $3.14 \mathrm{in}$ & $6.04 \mathrm{in}$ \\
\hline Measured & $\mathbf{2 . 0 5}$ in & $\mathbf{5 . 7 5}$ in & $\mathbf{6 . 2 9}$ in & $\mathbf{1 5 . 5 5}$ in \\
\hline
\end{tabular}

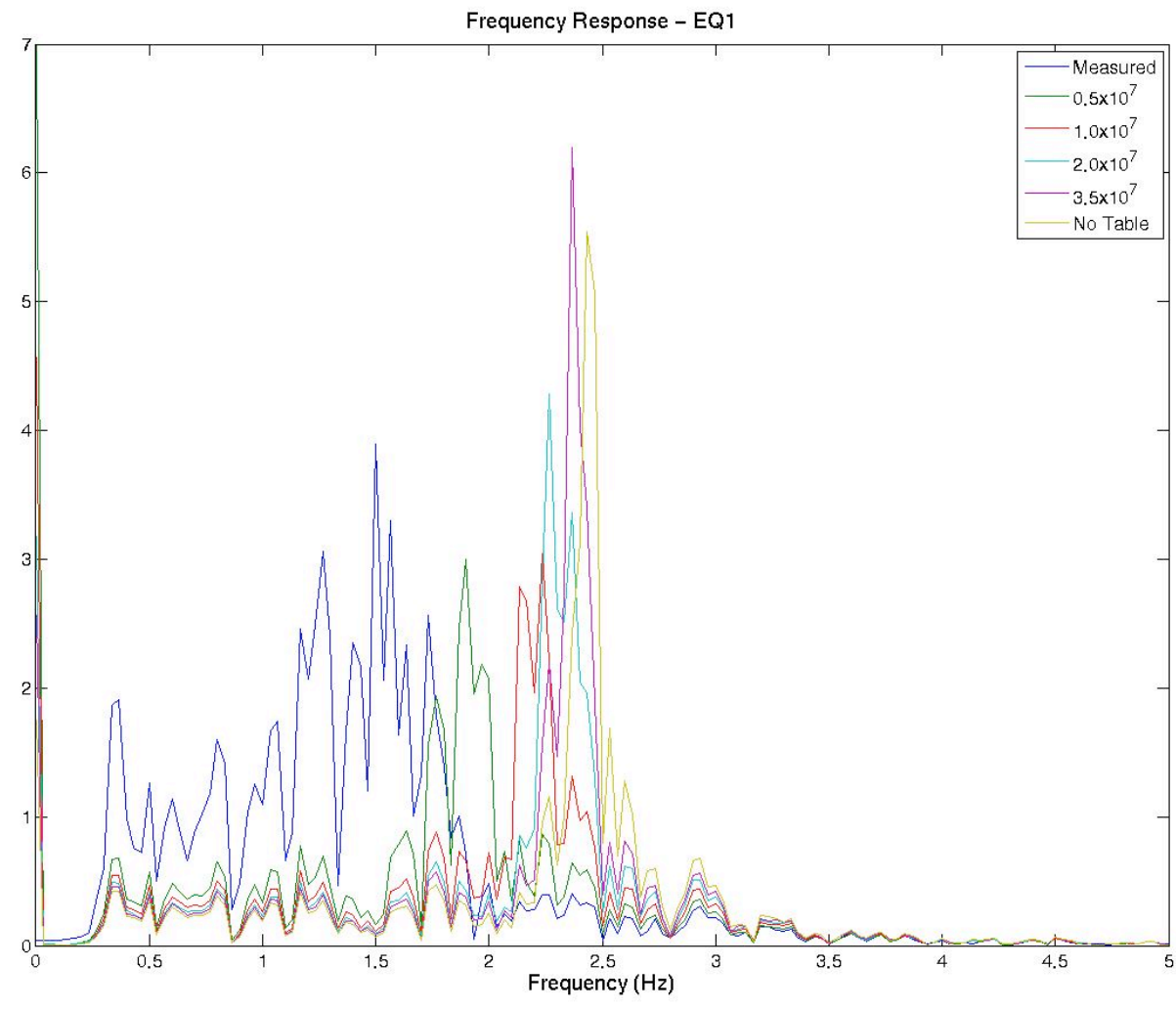

Figure 23. Frequency response of the simulated (linear model) roof displacements for the first earthquake compared to the frequency response of the measured roof displacement 


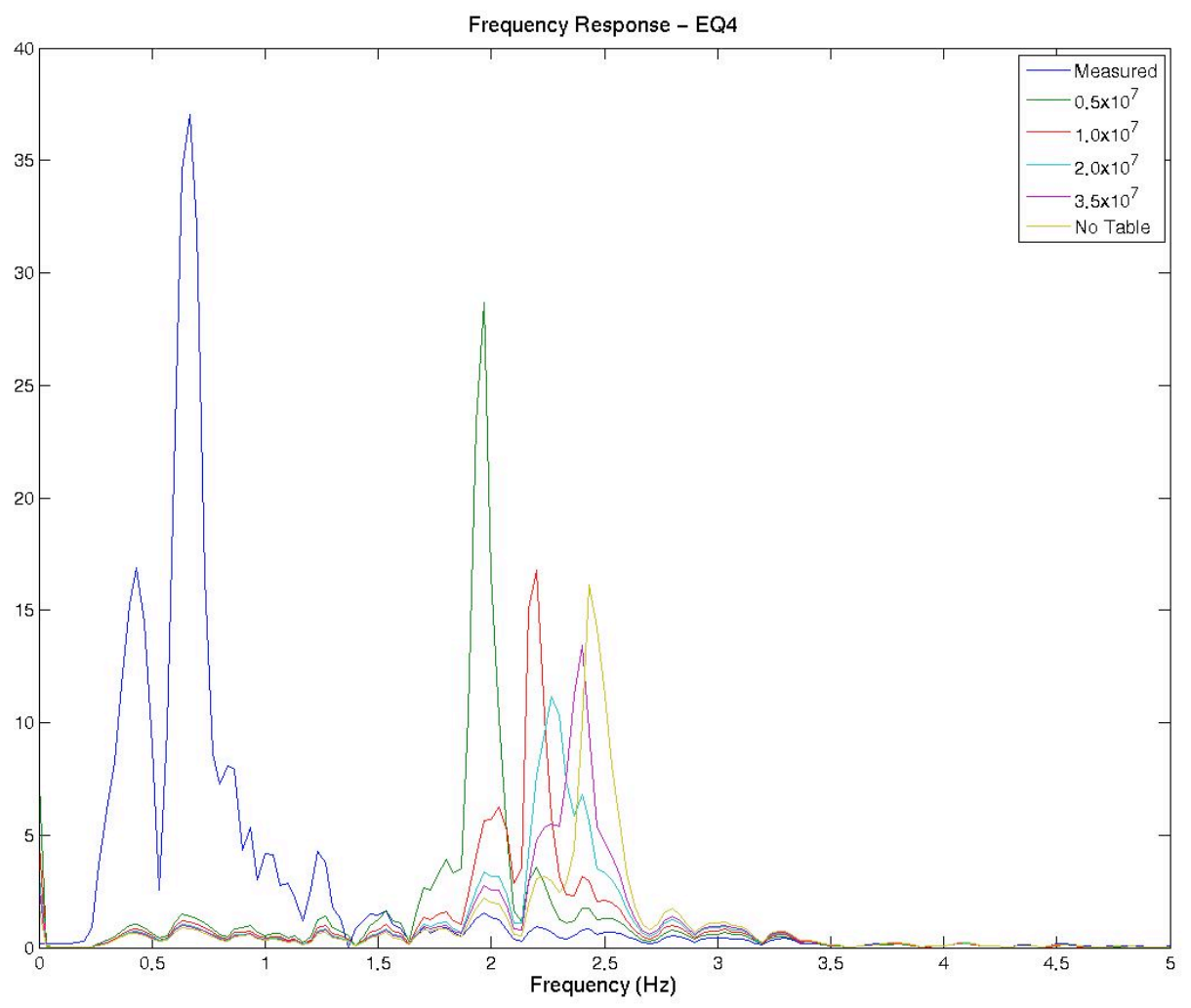

Figure 24. Frequency response of the simulated (linear model) roof displacements for the fourth earthquake compared to the frequency response of the measured roof displacement

The previous version of the linear model with averaged concrete properties and no table platen [7] computed responses yielding an even worse agreement with the measured response. The peak displacements computed for the four earthquakes were $0.92 \mathrm{in,} 1.91 \mathrm{in}, 2.81$ in and $4.92 \mathrm{in.}$ This is further evidence that the modeling of the floors with independent concrete properties is a necessary improvement to the model in order to simulate a realistic response.

\section{Nonlinear Dynamic Analyses}

The nonlinear model of the structure is similar to the linear model with discretization for the homogenized rebar (Figure 25). The homogenized concrete/rebar materials are material type 66 and the concrete materials are material type 45 [2]. Like the linear model, $2 \%$ of critical damping at $2.0 \mathrm{~Hz}$ is attained by mass proportional damping. Prior to performing any earthquake simulations, gravity and post-tensioned column initialization analyses were performed, and the final states were supplied as stress initialization for the first earthquake simulations. 


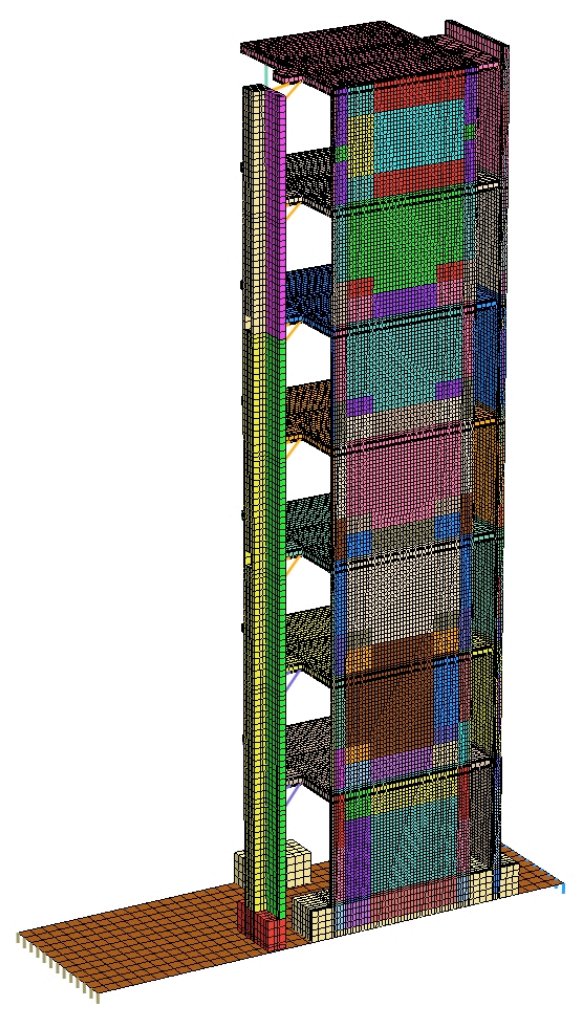

Figure 25. Finite element model of the structure with the shake table platen for nonlinear simulations in ParaDyn

Nonlinear analyses were performed for all five table platen variations for the first earthquake ground motion. The simulated roof displacements are compared to the measured roof displacement for the models with each of the table platen rotational stiffnesses and no table platen in Figure 26 through Figure 30. These results show that the model is too stiff (i.e., oscillates at a frequency that is too high) compared to the actual structure unless a rotational stiffness of $0.5 \times 10^{7} \mathrm{kip}$ - $\mathrm{ft} / \mathrm{rad}$ is used. Recall that $0.5 \times 10^{7} \mathrm{kip}-\mathrm{ft} / \mathrm{rad}$ is a lower bound for the rotational stiffnesses estimated by UCSD due to table and foundation flexibility (Table 4), and that foundation flexibility is believed to be underestimated in the model so inclusion of extra rotational flexibility in the table platen is appropriate. The computed nonlinear peak roof displacements (Table 7) generally agree better with the measured peak roof displacement than those computed from the linear model (Table 6), as would be expected. As is also expected, the computed peak roof displacements are in better agreement with the measured displacement than the result from the previous version of the nonlinear model with averaged concrete properties and no table platen, $1.47 \mathrm{in}$. 

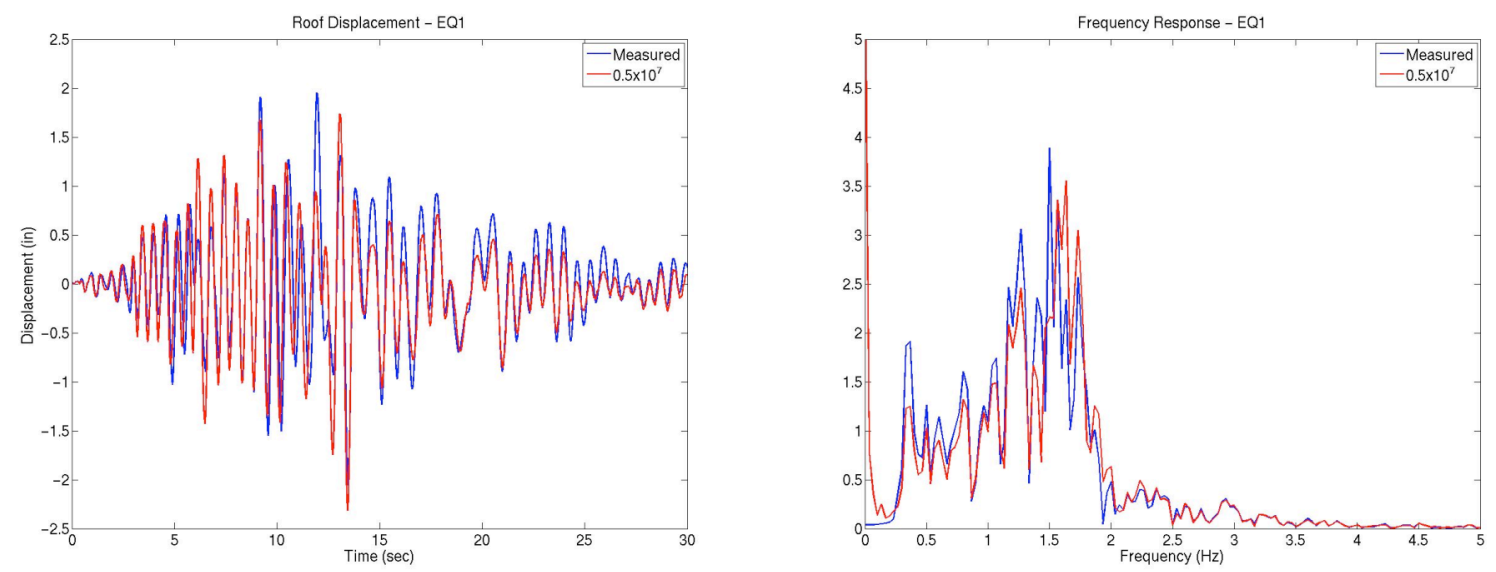

Figure 26. Time history (left) and frequency response (right) of the computed roof displacement for the model with a table platen rotational stiffness of $0.5 \times 10^{7} \mathrm{kip}-\mathrm{ft} / \mathrm{rad}$ compared to the measured roof displacement for the first earthquake
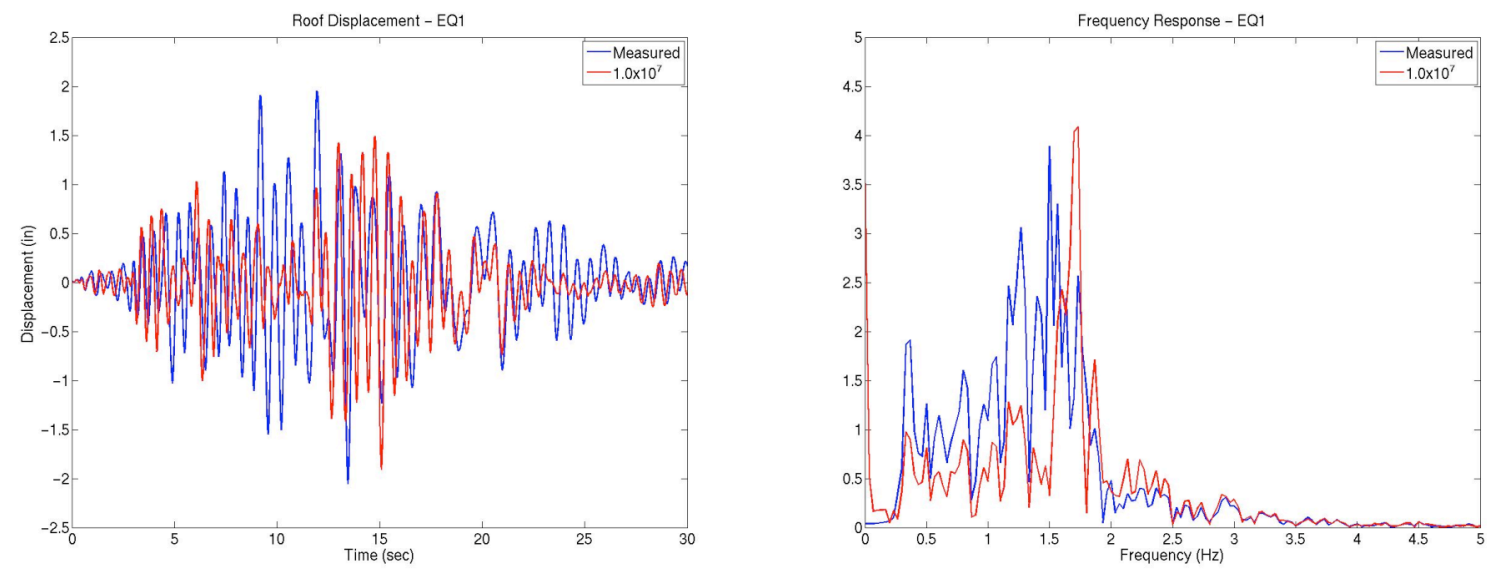

Figure 27. Time history (left) and frequency response (right) of the computed roof displacement for the model with a table platen rotational stiffness of $1.0 \times 10^{7} \mathrm{kip}-\mathrm{ft} / \mathrm{rad}$ compared to the measured roof displacement for the first earthquake 

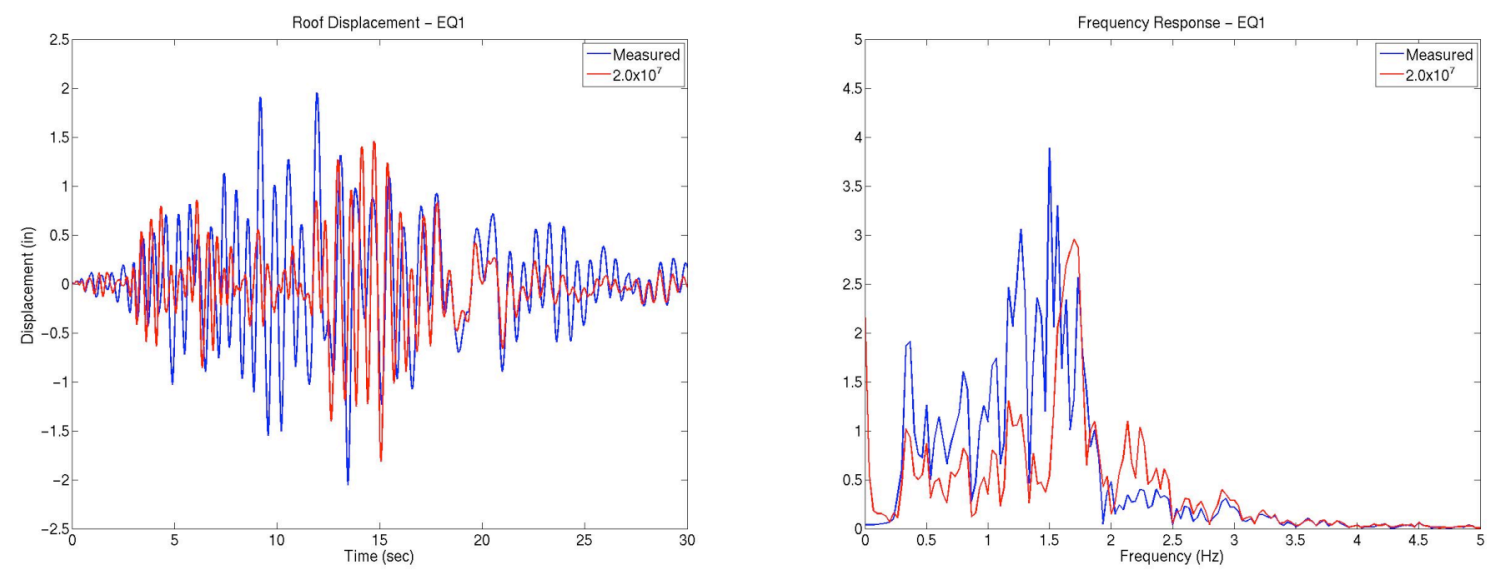

Figure 28. Time history (left) and frequency response (right) of the computed roof displacement for the model with a table platen rotational stiffness of $2.0 \times 10^{7} \mathrm{kip}-\mathrm{ft} / \mathrm{rad}$ compared to the measured roof displacement for the first earthquake
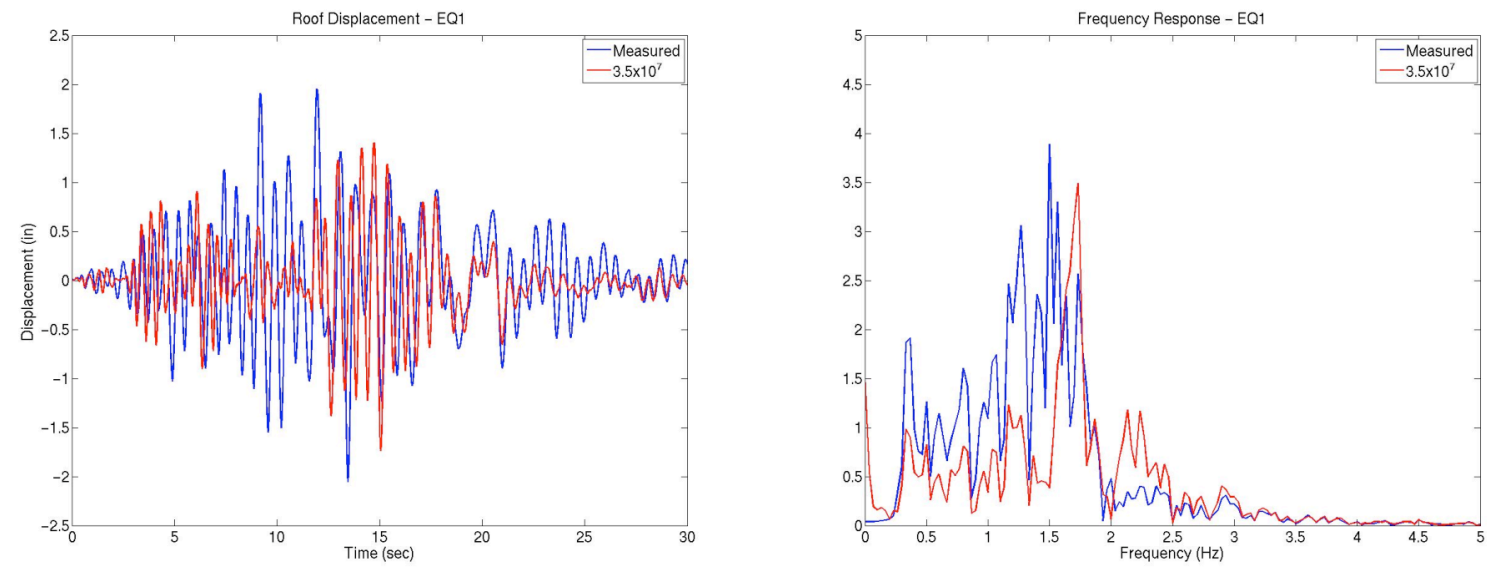

Figure 29. Time history (left) and frequency response (right) of the computed roof displacement for the model with a table platen rotational stiffness of $3.5 \times 10^{7} \mathrm{kip}-\mathrm{ft} / \mathrm{rad}$ compared to the measured roof displacement for the first earthquake 

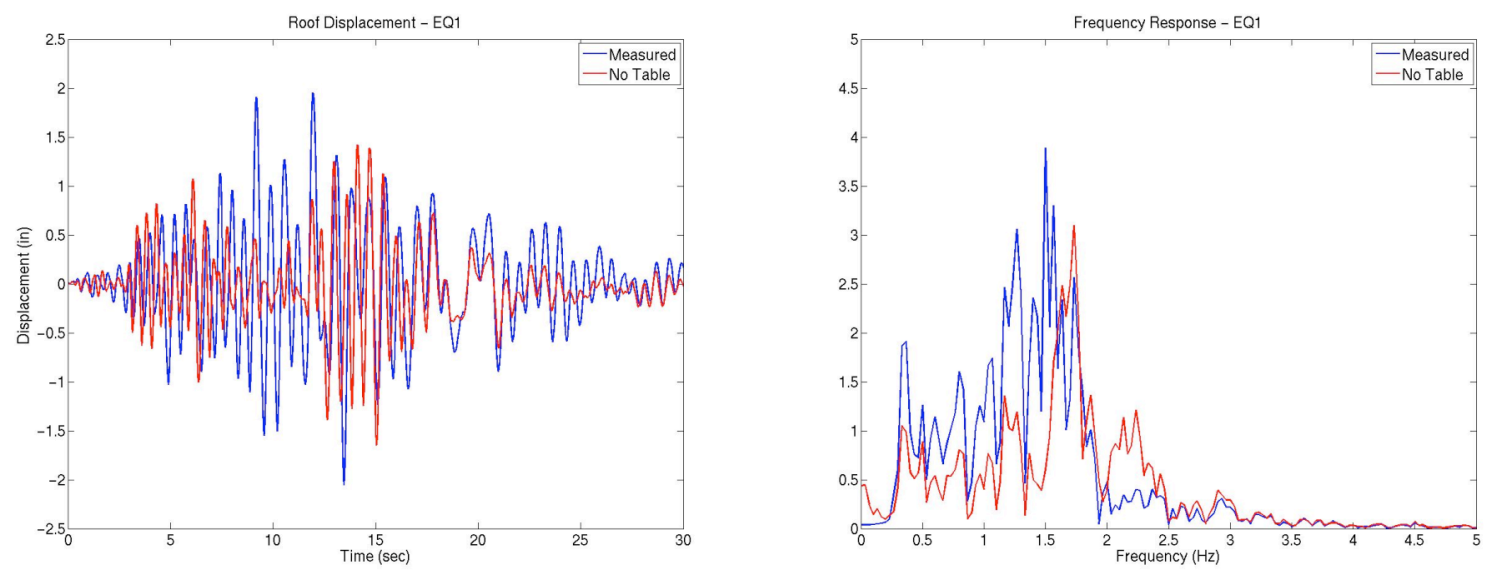

Figure 30. Time history (left) and frequency response (right) of the computed roof displacement for the model with no table platen compared to the measured roof displacement for the first earthquake

Table 7. Peak values of the simulated (nonlinear model) and measured roof displacement for the first earthquake ground motion

\begin{tabular}{|c|c|}
\hline $\begin{array}{c}\text { Rotational } \\
\text { Stiffness of Shake } \\
\text { Table Platen }\end{array}$ & EQ1 \\
\hline $0.5 \times 10^{7} \mathrm{kip}-\mathrm{ft} / \mathrm{rad}$ & $2.31 \mathrm{in}$ \\
\hline $1.0 \times 10^{7} \mathrm{kip}-\mathrm{ft} / \mathrm{rad}$ & $1.91 \mathrm{in}$ \\
\hline $2.0 \times 10^{7} \mathrm{kip}-\mathrm{ft} / \mathrm{rad}$ & $1.81 \mathrm{in}$ \\
\hline $3.5 \times 10^{7} \mathrm{kip}-\mathrm{ft} / \mathrm{rad}$ & $1.74 \mathrm{in}$ \\
\hline No Table & $1.65 \mathrm{in}$ \\
\hline Measured & $\mathbf{2 . 0 5} \mathrm{in}$ \\
\hline
\end{tabular}

While the model with a table platen rotational stiffness of $0.5 \times 10^{7} \mathrm{kip}-\mathrm{ft} / \mathrm{rad}$ yields the best agreement with measurements, the numerical anomaly described in Section 2.2 that leads to large element deformations caused by large increments in effective plastic strain and pressure occurs in an element at the top of the first level of the web wall near the flange wall. This deformation leads to a significant area of failed concrete, meaning the concrete only has a fraction of its original strength. This is illustrated in Figure 31. Recall that the damage measure is defined such that a value of 0 corresponds to no damage (blue areas), a value of 1 corresponds to reaching the maximum surface (green areas), and a value of 2 corresponds to reaching the residual surface (red areas). Despite the occurrence of the numerical anomaly, the results are believed to be reasonable. The fact that the agreement with the measured response is good indicates that the large amount of stiffness reduction caused by the failed concrete may be an approximation of a physical phenomenon. However, the authors caution users of the concrete material model that this behavior needs to be carefully observed and evaluated on a case-by-case basis. 

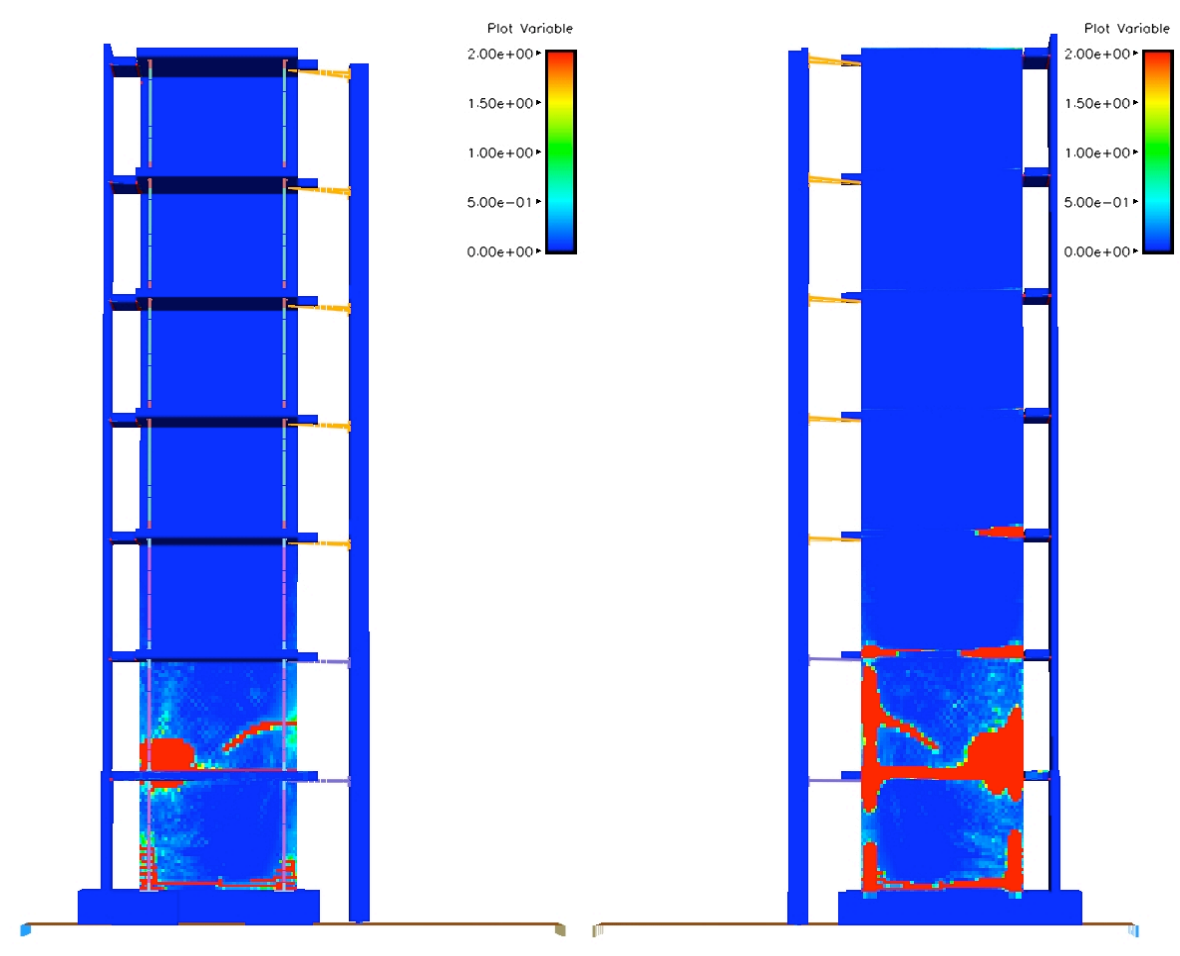

Figure 31. Concrete damage measure at the end of the first earthquake outside of the web wall (left) and in the middle of the web wall at the symmetry plane (right)

Simulations for the second and third earthquake ground motions were performed for the model with a table platen rotational stiffness of $0.5 \times 10^{7} \mathrm{kip}-\mathrm{ft} / \mathrm{rad}$, because that model displayed the best agreement with the recorded first earthquake response. Each earthquake simulation is stress initialized by the final state of the previous earthquake simulation following a period of relaxation to bring the structure to rest. The large element deformation caused by the numerical anomaly decreased the time step for the analysis, so prior to performing analyses for the second earthquake the element in question was deleted from the model. Simulations were also performed for the model with no table platen for comparison. The computed roof displacements for these two models are compared to the measured roof displacements for the second and third earthquakes in Figure 32 through Figure 35. For both earthquakes, the computed responses for both models agree well with the measured response initially. However, the computed responses deviate from the measured response at later times by underestimating the amplitude and getting out-of-phase to some extent. The level of agreement is generally worse for the third earthquake than the second earthquake. The agreement is generally better with table platen rotation for both earthquakes, as it was for the first earthquake. 

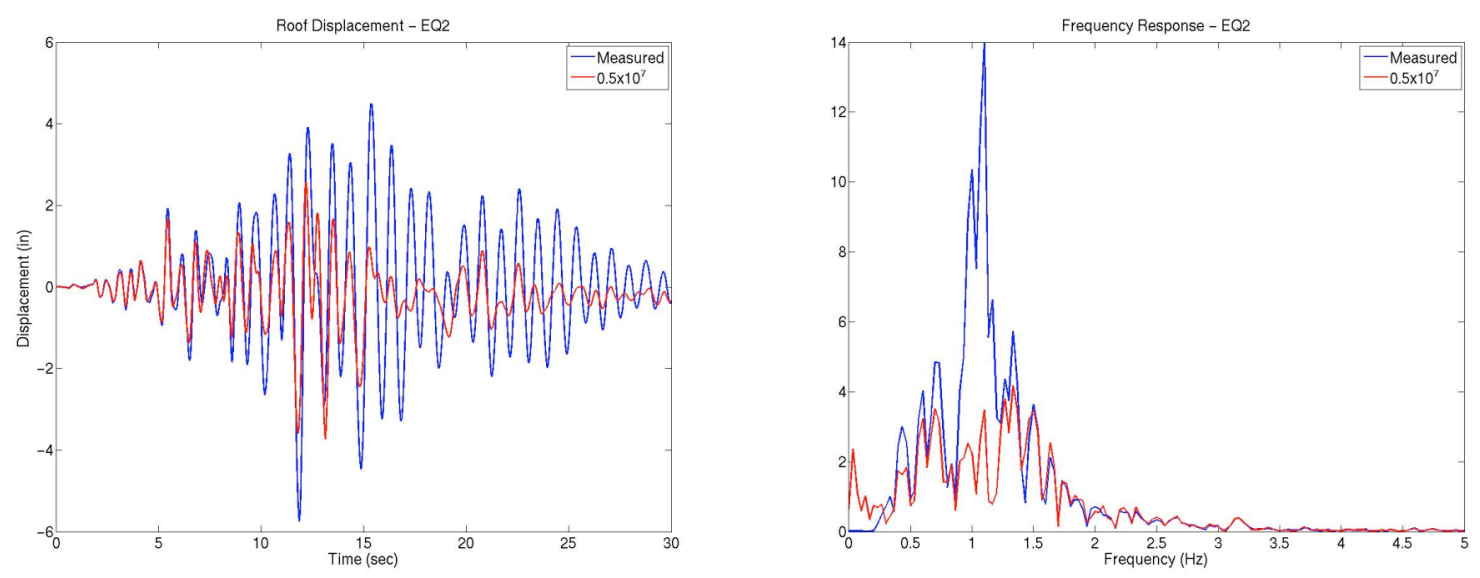

Figure 32. Time history (left) and frequency response (right) of the computed roof displacement for the model with a table platen rotational stiffness of $0.5 \times 10^{7} \mathrm{kip}-\mathrm{ft} / \mathrm{rad}$ compared to the measured roof displacement for the second earthquake
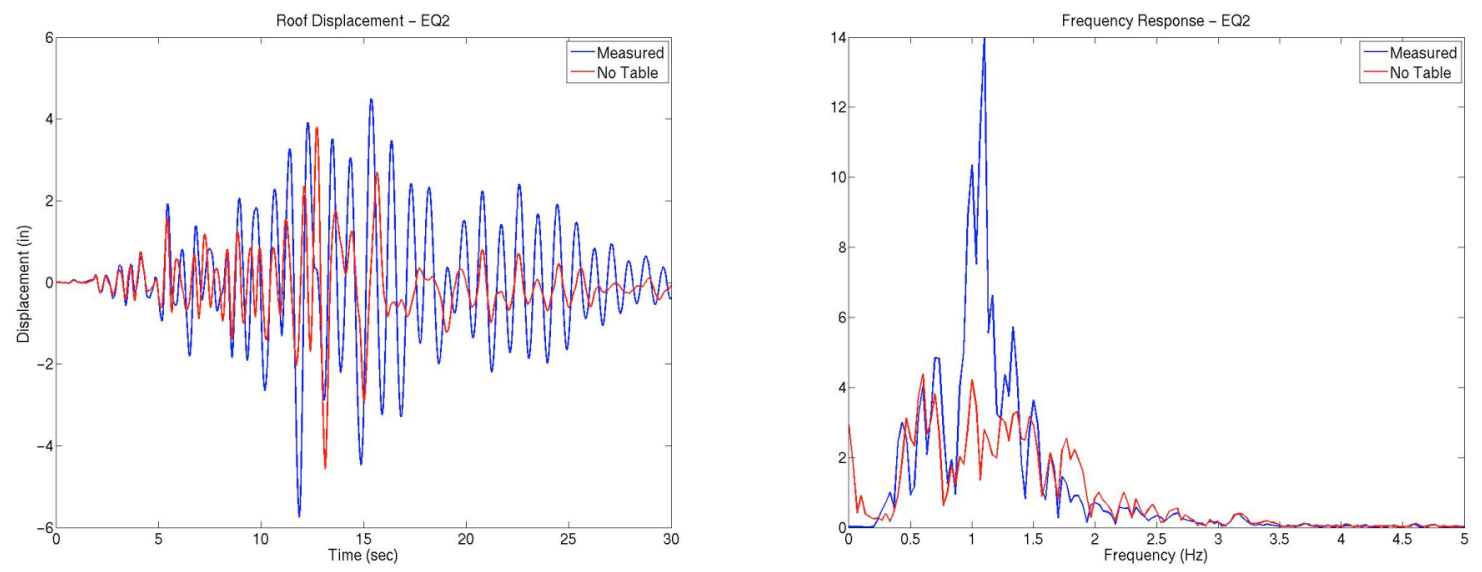

Figure 33. Time history (left) and frequency response (right) of the computed roof displacement for the model with no table platen compared to the measured roof displacement for the second earthquake 

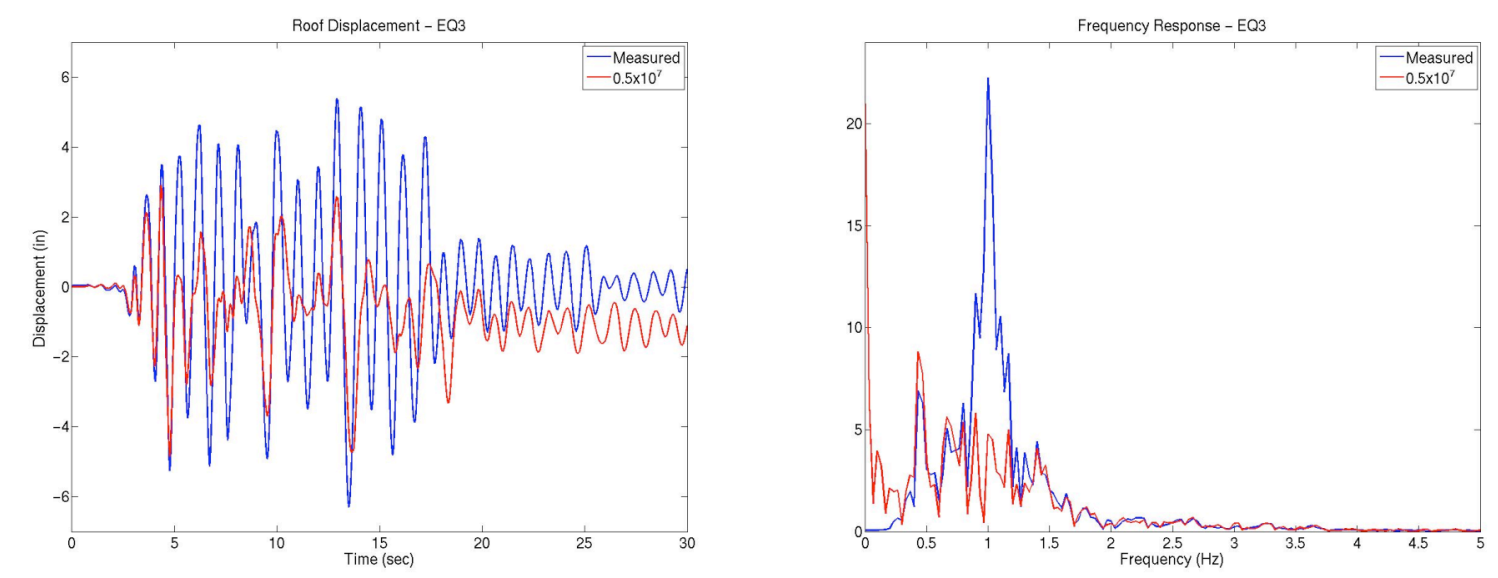

Figure 34. Time history (left) and frequency response (right) of the computed roof displacement for the model with a table platen rotational stiffness of $0.5 \times 10^{7} \mathrm{kip}-\mathrm{ft} / \mathrm{rad}$ compared to the measured roof displacement for the third earthquake
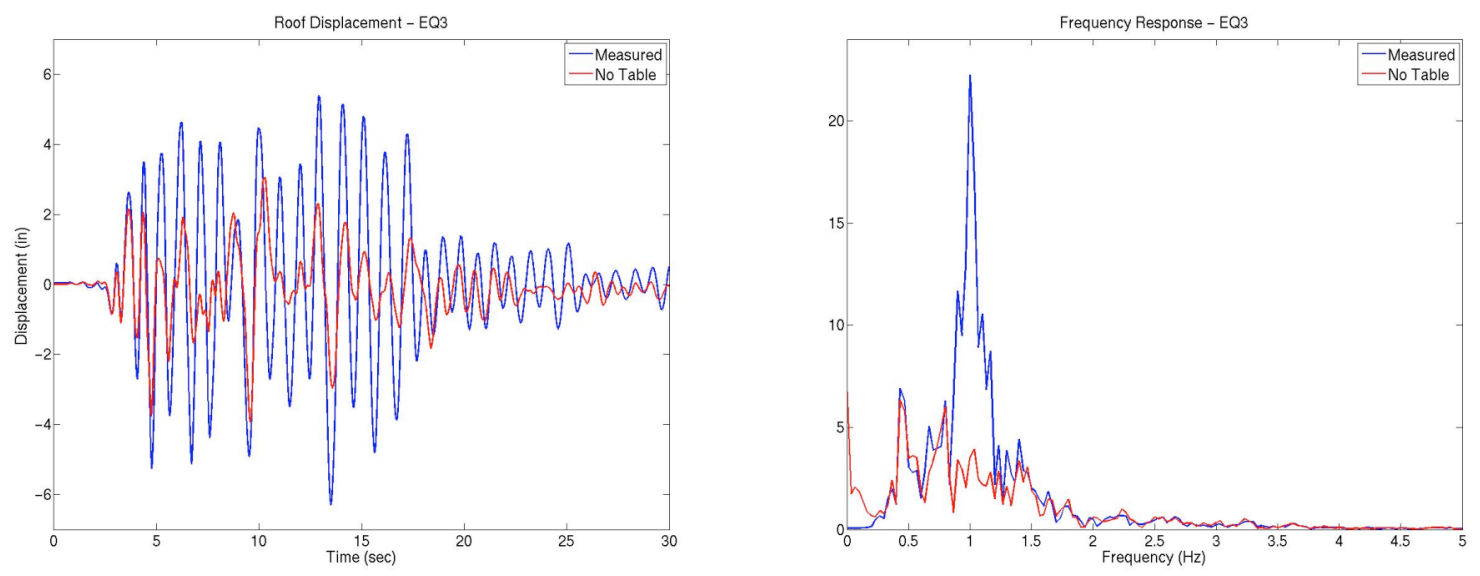

Figure 35. Time history (left) and frequency response (right) of the computed roof displacement for the model with no table platen compared to the measured roof displacement for the third earthquake

It is possible that the progressively worse agreement of the model from the first earthquake through the third earthquake is related to the amount of damping defined for the model. The damping is $2 \%$ at a frequency of $2.0 \mathrm{~Hz}$, and it is mass proportional. This means that the fraction of damping increases with decreasing frequency, e.g. $4 \%$ at $1.0 \mathrm{~Hz}$. Thus, while the prescribed damping may be appropriate for the first earthquake response, the damping may become too high as the model is progressively damaged and the stiffness decreases. This theory was tested by performing additional analyses for the second and third earthquakes with the model including table platen rotational stiffness at $0.5 \times 10^{7} \mathrm{kip}-\mathrm{ft} / \mathrm{rad}$. For these analyses, the damping was changed to be $1 \%$ of critical at $1.0 \mathrm{~Hz}$. The roof displacements computed from these analyses are compared to the original analyses and the measured responses in Figure 36 and Figure 37. The agreement for the second earthquake is somewhat improved with reduced damping, but the 
same cannot be said for the third earthquake. These results indicate that while inaccuracy in damping may cause a portion of the modeling discrepancies, damping is not the dominant factor.
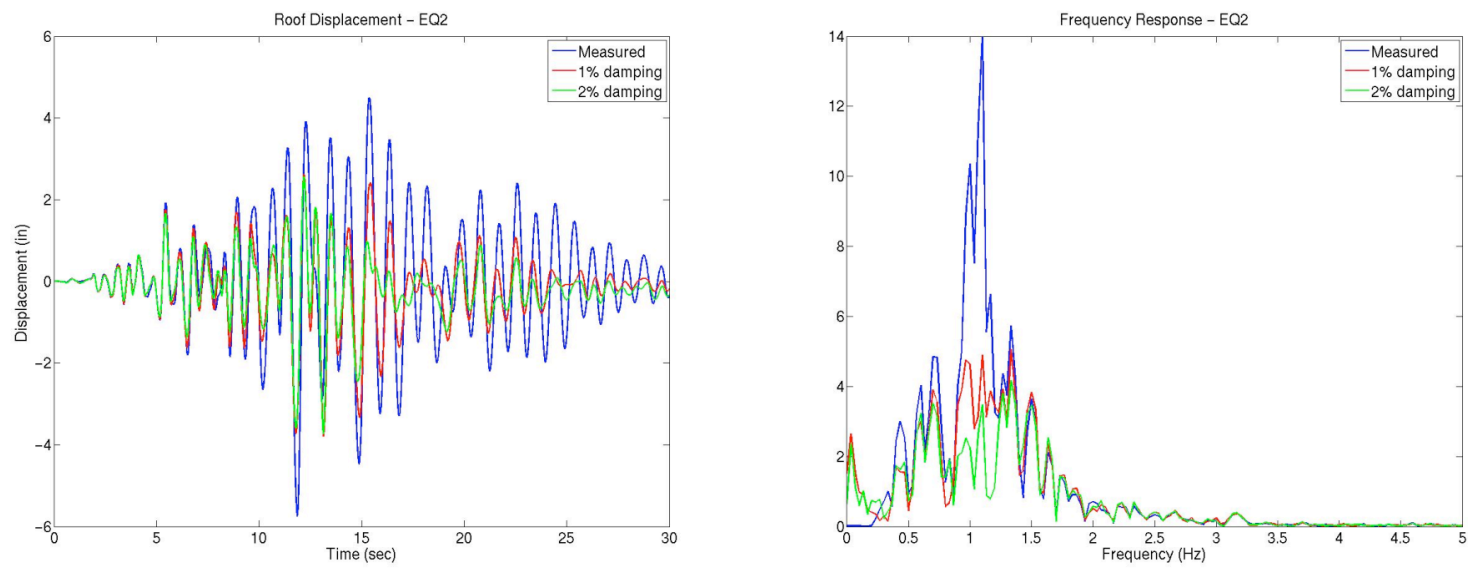

Figure 36. Time history (left) and frequency response (right) of the computed roof displacement for two levels of damping in the model with a table platen rotational stiffness of $0.5 \times 10^{7} \mathrm{kip}-\mathrm{ft} / \mathrm{rad}$ compared to the measured roof displacement for the second earthquake
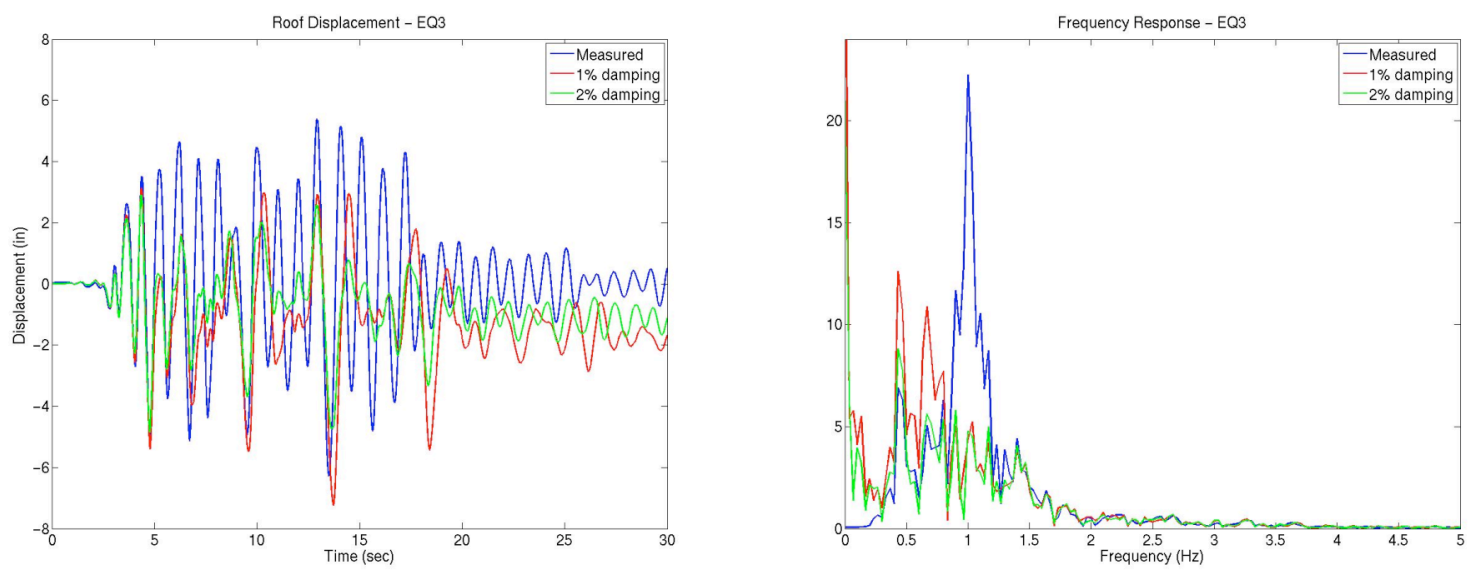

Figure 37. Time history (left) and frequency response (right) of the computed roof displacement for two levels of damping in the model with a table platen rotational stiffness of $0.5 \times 10^{7} \mathrm{kip}-\mathrm{ft} / \mathrm{rad}$ compared to the measured roof displacement for the third earthquake

The choice of the "lambda stretch" factor [2] for the concrete model was also investigated. Analyses with $\mathrm{s}=100$ were performed using the model with a table platen rotational stiffness of $0.5 \times 10^{7} \mathrm{kip}-\mathrm{ft} / \mathrm{rad}$ for the first and second earthquakes. The value of $\mathrm{s}=50$ was used for all other analyses. A "lambda stretch" factor of $s=100$ provides the maximum enhanced strength with increasing rate. The numerical anomaly causing large element deformation does not occur for this version of the model, but as can be seen from the first earthquake response (Figure 38), the model with stronger concrete computes a response that is a little too stiff. This is further 
indication that the effect of the numerical anomaly that occurs with $\mathrm{s}=50$ may be partially physical. Figure 39 shows the comparison for the second earthquake. At some times, $\mathrm{s}=100$ yields a slightly better agreement with the measured displacement, and at other times the agreement is worse than $\mathrm{s}=50$. Despite these observations, it is apparent from both Figure 38 and Figure 39 that the differences between using $\mathrm{s}=50$ and $\mathrm{s}=100$ are not that significant compared to the differences with the measured response, so the choice of the "lambda stretch" factor is not believed to be a crucial modeling decision.
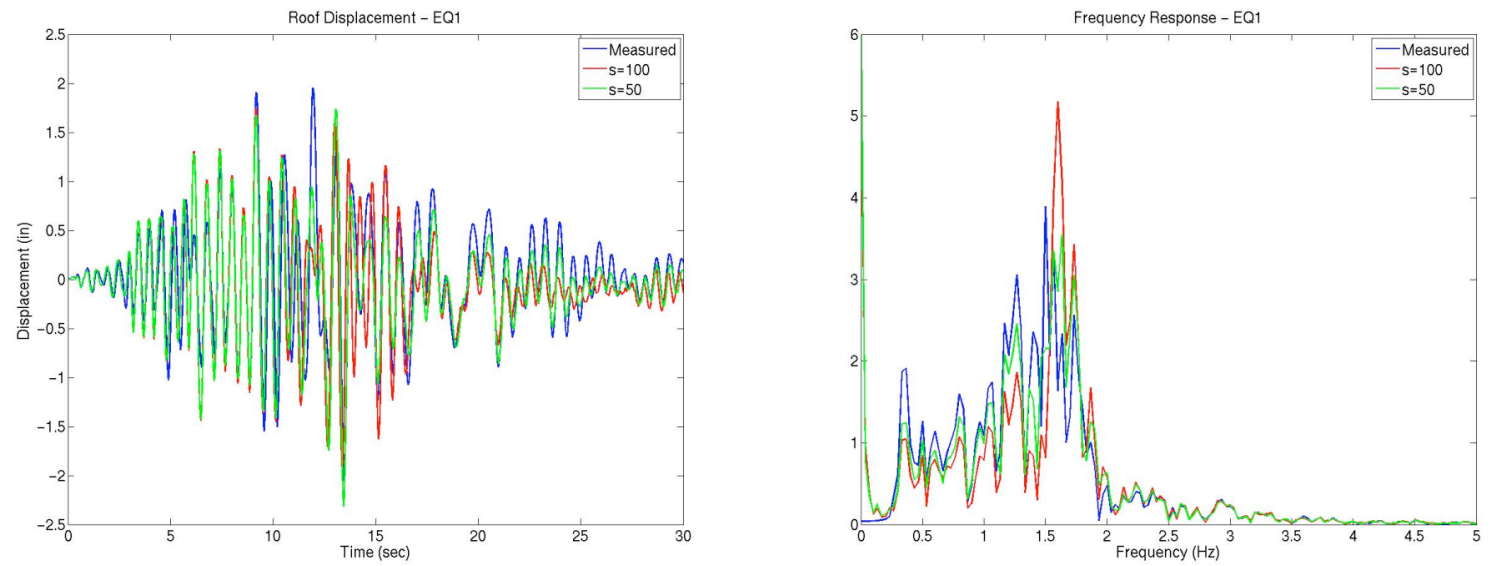

Figure 38. Time history (left) and frequency response (right) of the computed roof displacement for two "lambda stretch" factors in the model with a table platen rotational stiffness of $0.5 \times 10^{7} \mathrm{kip}-\mathrm{ft} / \mathrm{rad}$ compared to the measured roof displacement for the first earthquake
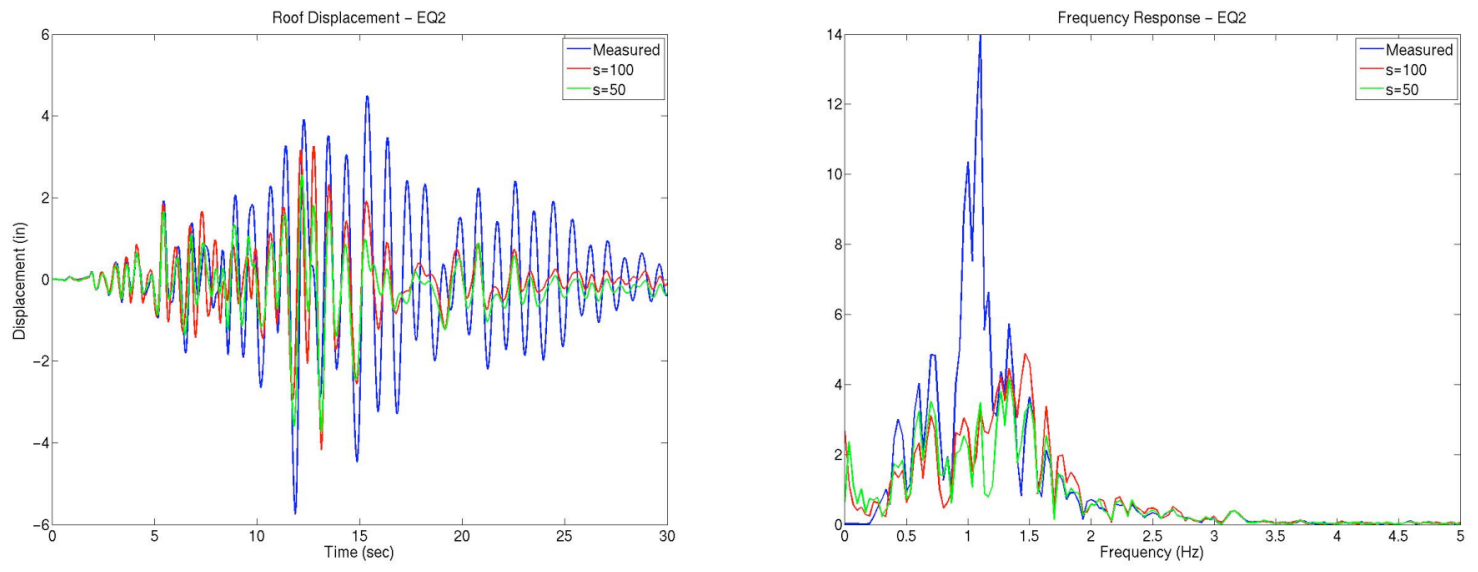

Figure 39. Time history (left) and frequency response (right) of the computed roof displacement for two "lambda stretch" factors in the model with a table platen rotational stiffness of $0.5 \times 10^{7} \mathrm{kip}-\mathrm{ft} / \mathrm{rad}$ compared to the measured roof displacement for the second earthquake 
Simulations were performed for the fourth earthquake even though the results were not expected to agree with the measured response based on observations of the simulations for the second and third earthquakes. These simulations for the fourth earthquake use the original $2 \%$ damping at $2.0 \mathrm{~Hz}$. The computed roof displacements for the models with and without table platen rotation are shown in Figure 40 and Figure 41, respectively. As anticipated the agreement with the measured displacement is not good. The initial pulse is approximated fairly well by both models, but then the oscillation frequency of the computed response becomes far too low. This occurs because the model becomes heavily damaged early in the fourth earthquake simulation. Figure 42 shows the concrete damage measure for the model with table platen rotation before the fourth earthquake, and Figure 43 shows the damage measure at the end of the fourth earthquake. While the model has been quite significantly damaged after the first three earthquakes, the damage caused by the fourth earthquake is very heavy.
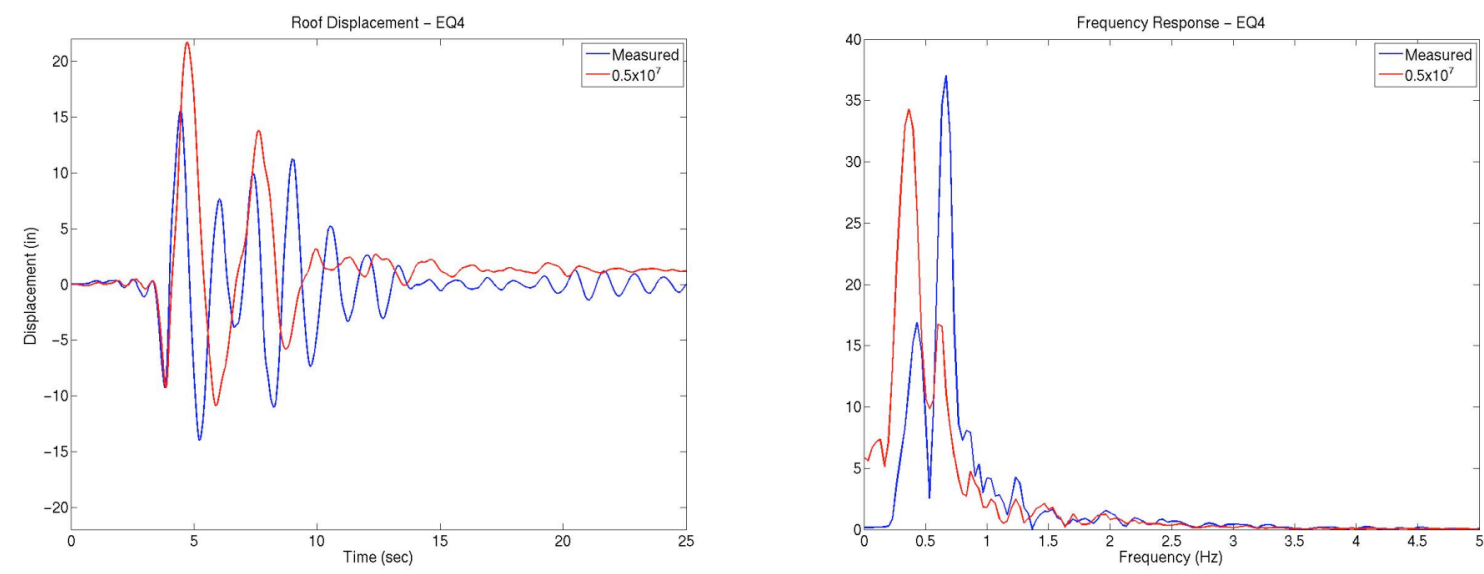

Figure 40. Time history (left) and frequency response (right) of the computed roof displacement for the model with a table platen rotational stiffness of $0.5 \times 10^{7} \mathrm{kip}-\mathrm{ft} / \mathrm{rad}$ compared to the measured roof displacement for the fourth earthquake
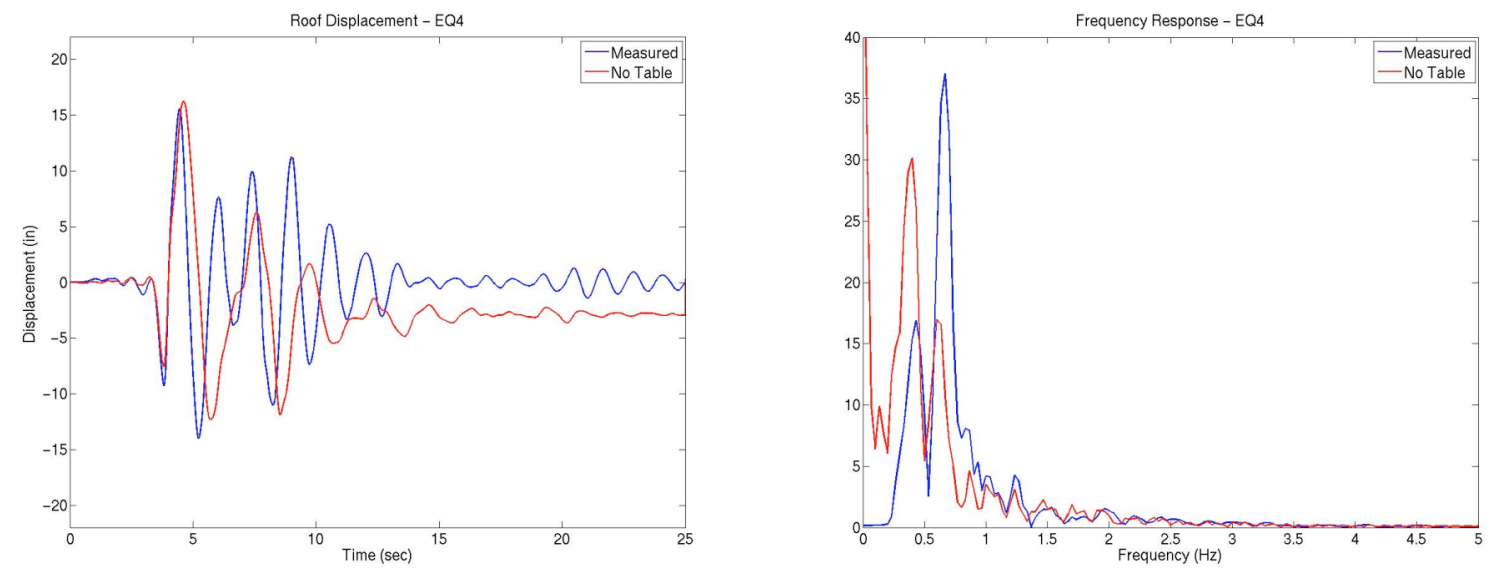

Figure 41. Time history (left) and frequency response (right) of the computed roof displacement for the model with no table platen compared to the measured roof displacement for the fourth earthquake 

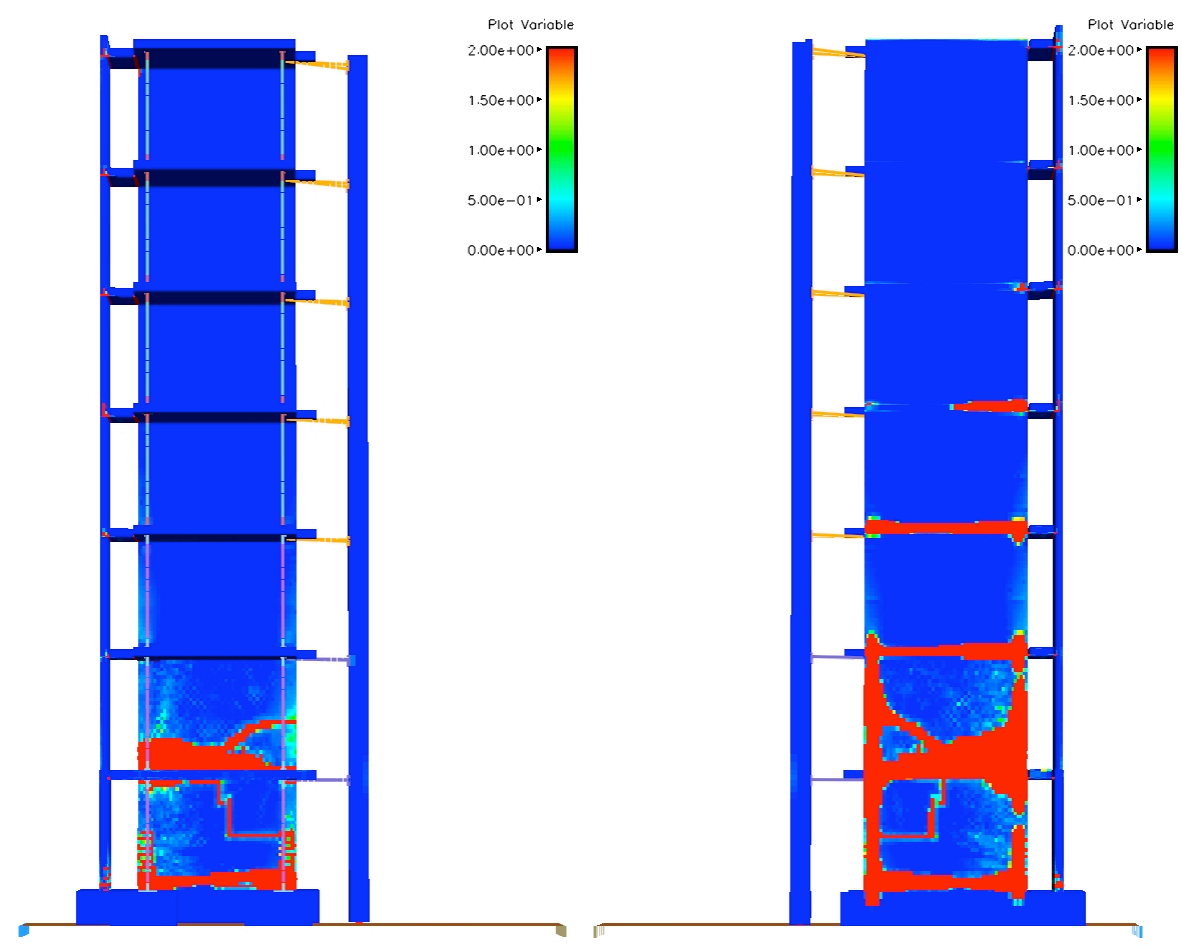

Figure 42. Concrete damage measure at the start of the fourth earthquake outside of the web wall (left) and in the middle of the web wall at the symmetry plane (right)
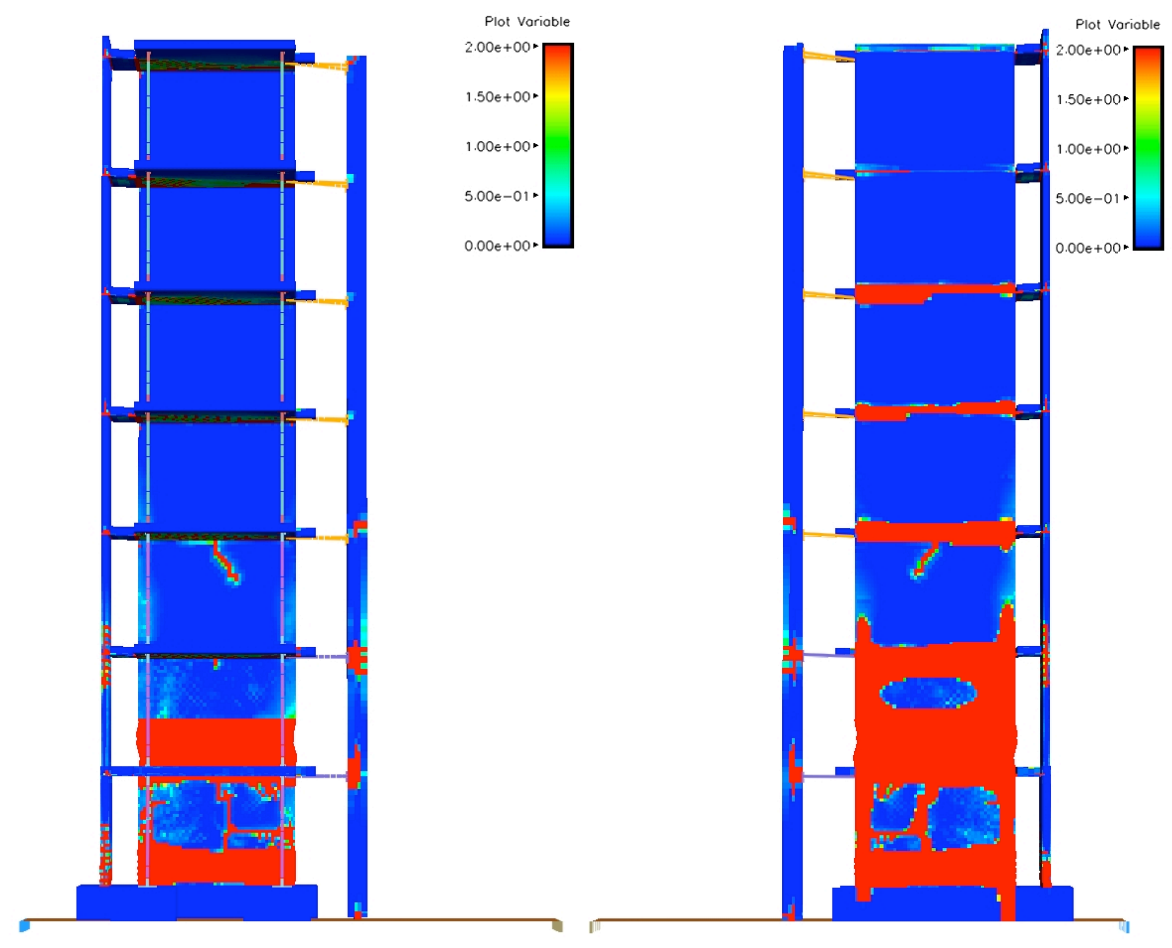

Figure 43. Concrete damage measure at the end of the fourth earthquake outside of the web wall (left) and in the middle of the web wall at the symmetry plane (right) 
The authors believe that the extensive amount of concrete damage and the associated overly soft computed response may be evidence that the concrete model does not retain enough strength after it has reached the maximum and residual failure surfaces. Thus, the damage measure is believed to be a reasonable metric for determining initial damage, but may not be physically meaningful for long duration simulations with significant levels of damage.

\section{Conclusions}

It is believed that the use of the homogenized rebar model in DYNA3D/ParaDyn has been partially validated for use in seismic simulations of reinforced concrete structures. The results from the model are physically reasonable, and good agreement is demonstrated with the experiment for the first earthquake motion. However, difficulties persist in the modeling approach for long seismic durations.

While the numerical instability causing code termination has been corrected, there is still concern about the large deformations caused by the numerical anomaly that is still present in the material model. In any situation where the anomaly occurs, judgment must be utilized to assess whether the behavior is physically reasonable, and in order to continue simulations after an element deforms, it may be necessary to delete the element for reasons of computational efficiency. It may also be possible to slightly modify model parameters to avoid occurrence of the anomaly. However, these are only temporary solutions. The ultimate solution must be modification of the material model in DYNA3D. In the meantime, it should be made clear that the authors do not believe the existence of the numerical anomaly invalidates the response of the concrete model, but care must always be taken in interpreting the results.

It is also important to understand that accurate modeling of a reinforced concrete structure using DYNA3D/ParaDyn requires that attention be paid to defining accurate material properties and boundary conditions. A previous version of the model that was defined with higher resolution for the rebar discretization, but less accurate concrete properties, did not compare well to the experiment. This indicates that while it is necessary to define the concrete properties as accurately as possible, the definition of the homogenized rebar does not necessarily require a very high level of detail.

The definition of damping is often a significant source of uncertainty when performing seismic simulations of a structure. The analyses described in this report are no exception. Attention should be paid to defining physically reasonable damping, and perhaps, it is necessary to modify the prescribed damping during simulations as the structure is progressively damaged and the natural frequencies decrease.

Perhaps even more important than the material properties and damping, it is crucial to accurately define boundary conditions of the model. The inclusion of a rotational stiffness for the shake table platen is an important component for representing the conditions of the experiment. Without that boundary condition, it was not possible to assess the capabilities of the homogenized concrete/rebar model, because the system was incorrect. This is a problem that exists with any full-scale seismic experiment of a large structure since interaction with a shake table would be a major contributor to the response. There were other uncertainties in the 
experiment that could have affected the modeling effort. One example of this was the state of the braces connecting the post-tensioned column to the floor slabs. The variations in that boundary condition were not modeled because the significance is believed to be small, but it is possible that the importance is greater than anticipated. This could be especially true for the successively larger earthquakes, for which nonlinearity was dominant and the agreement with the experiment was not good. Typically, these boundary condition concerns would not be an issue for an actual functioning structure that required seismic modeling, because the boundary conditions are largely necessitated by the experiment itself. Therefore, these issues may not be as important in practice, but they do complicate the validation efforts.

The comparison of the simulated response to the experimental response is primarily based on the comparison of displacement. However, the damage evolution of the concrete is indirectly compared by observing changes in the natural frequencies of the structure. Decreases in oscillation frequency indicate that the structure is being progressively damaged. The early behavior of the concrete model appears to be a good physical approximation of the actual structure, but as the simulations progress and the concrete strength is increasingly degraded, the residual strength of the concrete model appears as though it may be too weak. Thus, it is believed that the concrete model provides reasonable results for determining the onset of structural damage during a seismic event, but performing very long duration seismic analyses with progressive stages of damage may not be viable at this time with the concrete and homogenized rebar models in DYNA3D.

The validation efforts described in this report focused on comparing the simulated roof displacement to the roof displacement measured during the experiment. This is a good metric for overall system response, but the experimental structure was heavily instrumented with accelerometers and strain gauges. The large amount of data obtained from these instruments could potentially be used in future model validation studies.

\section{Acknowledgements}

We would like to thank NEES, UC San Diego, Marios Panagiotou, Ruben Soto and Professors Joel Conte and Jose Restrepo for providing information about the structure and results of the experiment; and we would like to thank the Methods Development Group at LLNL and Rich Becker for aiding the authors in the modification of material type 45 in DYNA3D.

\section{References}

1. NEEScentral. NEES Cyberinfrastructure Center. $<$ https://central.nees.org $>$.

2. Lin, J.I. DYNA3D: A Nonlinear, Explicit, Three-Dimensional Finite Element Code for Solid and Structural Mechanics, User Manual. Lawrence Livermore National Laboratory. Report No. UCRL-MA-107254, June 2005.

3. Hoover, C.G., A.J. De Groot, and R.J. Sherwood. ParaDyn User Manual, ParaDyn: A Parallel Nonlinear Explicit, Three-Dimensional Finite-Element Code for Solid and Structural Mechanics. Lawrence Livermore National Laboratory. Report No. UCRL-MA140943-revised, January 2004. 
4. Noble, C., E. Kokko, I. Darnell, T. Dunn, L. Hagler, and L. Leininger. Concrete Model Descriptions and Summary of Benchmark Studies for Blast Effects Simulations. Lawrence Livermore National Laboratory. Report No. UCRL-TR-215024, July 2005.

5. Malvar, L.J., J.E. Crawford, J.W. Wesevich, and D. Simons. A New Concrete Material Model for DYNA3D. Karagozian \& Case. Report No. TR-94-14.3, December 5, 1994.

6. Malvar, L.J., J.E. Crawford, J.W. Wesevich, and D. Simons. A New Concrete Material Model for DYNA3D Release II: Shear Dilation and Directional Rate Enhancements. Karagozian \& Case. Report No. TR-96-2.2, February 8, 1996.

7. Alves, S.W. and C.R. Noble. Experimental Validation of LLNL Finite Element Codes for Nonlinear Seismic Simulations (Progress, Year 1 of 2). Lawrence Livermore National Laboratory. Report No. UCRL-TR-226690, September 2006.

8. Malvar, L.J., J.E. Crawford, K.B. Morrill. K\&C Concrete Material Model Release IIIAutomated Generation of Material Model Input. Karagozian \& Case. Report No. TR-9924.3, August 18, 2000.

9. Puso, M.A., B.N. Maker, R.M. Ferencz, and J.O. Hallquist. NIKE3D, A Nonlinear, Implicit, Three-Dimensional Finite Element Code for Solid and Structural Mechanics, User's Manual. Lawrence Livermore National Laboratory. Report No. UCRL-MA-105268 Rev. 1, June 7, 2004. 